\title{
BMJ Open Mask shortage during epidemics and pandemics: a scoping review of interventions to overcome limited supply
}

\author{
Abirami Kirubarajan (D) , ${ }^{1,2}$ Shawn Khan, ${ }^{1}$ Tiffany Got, ${ }^{1}$ Matthew Yau, ${ }^{1,2}$ \\ Jennifer M Bryan, ${ }^{3,4}$ Steven Marc Friedman (i) ${ }^{4,5}$
}

To cite: Kirubarajan A, Khan S, Got T, et al. Mask shortage during epidemics and pandemics: a scoping review of interventions to overcome limited supply. BMJ Open 2020;10:e040547. doi:10.1136/ bmjopen-2020-040547

- Prepublication history and supplemental material for this paper is available online. To view these files, please visit the journal online (http://dx.doi. org/10.1136/bmjopen-2020040547).

Received 19 May 2020 Revised 13 October 2020 Accepted 02 November 2020

\section{ABSTRACT}

Objective To characterise published evidence regarding preclinical and clinical interventions to overcome mask shortages during epidemics and pandemics.

Design Systematic scoping review.

Settings All healthcare settings relevant to epidemics and pandemics.

Search strategy English peer-reviewed studies published from January 1995 to June 2020 were included. Literature was identified using four databases (Medline-OVID, EMBASE, CINAHL, Cochrane Library), forwards-andbackwards searching through Scopus and an extensive grey literature search. Assessment of study eligibility, data extraction and evidence appraisal were performed in duplicate by two independent reviewers.

Results Of the 11220 database citations, a total of 47 articles were included. These studies encompassed six broad categories of conservation strategies: decontamination, reusability of disposable masks and/ or extended wear, layering, reusable respirators, nontraditional replacements or modifications and stockpiled masks. Promising strategies for mask conservation in the context of pandemics and epidemics include use of stockpiled masks, extended wear of disposable masks and decontamination.

Conclusion There are promising strategies for overcoming face mask shortages during epidemics and pandemics. Further research specific to practical considerations is required before implementation during the COVID-19 pandemic.

\section{INTRODUCTION}

Face masks, including surgical masks and N95 respirators (table 1), are integral components of personal protective equipment (PPE) to protect healthcare workers (HCWs) from transmission of viral and bacterial pathogens. ${ }^{1}$ They are essential for the prevention of nosocomial infection of the current COVID-19 pandemic. $^{2}$ The Centers for Disease Control and Prevention (CDC), WHO and expert bodies have highlighted the importance of appropriate PPE to prevent nosocomial infection of HCWs, as well as to limit the
Strengths and limitations of this study

- This is the first scoping review of the literature that has evaluated the evidence behind overcoming mask shortages during pandemics and epidemics, which is increasingly relevant during the COVID-19 pandemic

- Strengths of design include the robust search strategy, thorough grey literature search, registration of protocol, multiple evidence appraisals and completion of all steps in duplicate with two reviewers.

- Limitations include the limits of the evidence base and limitation to the English language.

global spread of the virus. ${ }^{3-5}$ While there is controversy regarding whether community members should wear masks in public, there is a consensus that healthcare providers have greater risk of exposure and require protection. ${ }^{67}$ The consequences of limited or inappropriate use of PPE for healthcare providers has been demonstrated in previous epidemics and pandemics, including SARS, Ebolavirus and H1N1 influenza A. ${ }^{8-10}$

Recently, WHO has called attention to shortages in face masks during the COVID-19 pandemic. $^{11}$ The causes of these shortages are multifactorial, including increased demand for masks both by HCWs worldwide, and disruptions in the global supply chain through a large reduction in exports from China, a major producer of medical grade masks. ${ }^{12}$ Hoarding and misuse by lay people further compromises supply in times of mass panic. ${ }^{2}$ Given the currently high rate of infection of providers with COVID-19, ${ }^{13} 14$ maintaining an adequate supply for them is a matter of urgency.

Strategies for overcoming the limited supply of masks in this time of public health crisis are being prioritised by medical bodies. The CDC has released a document outlining 


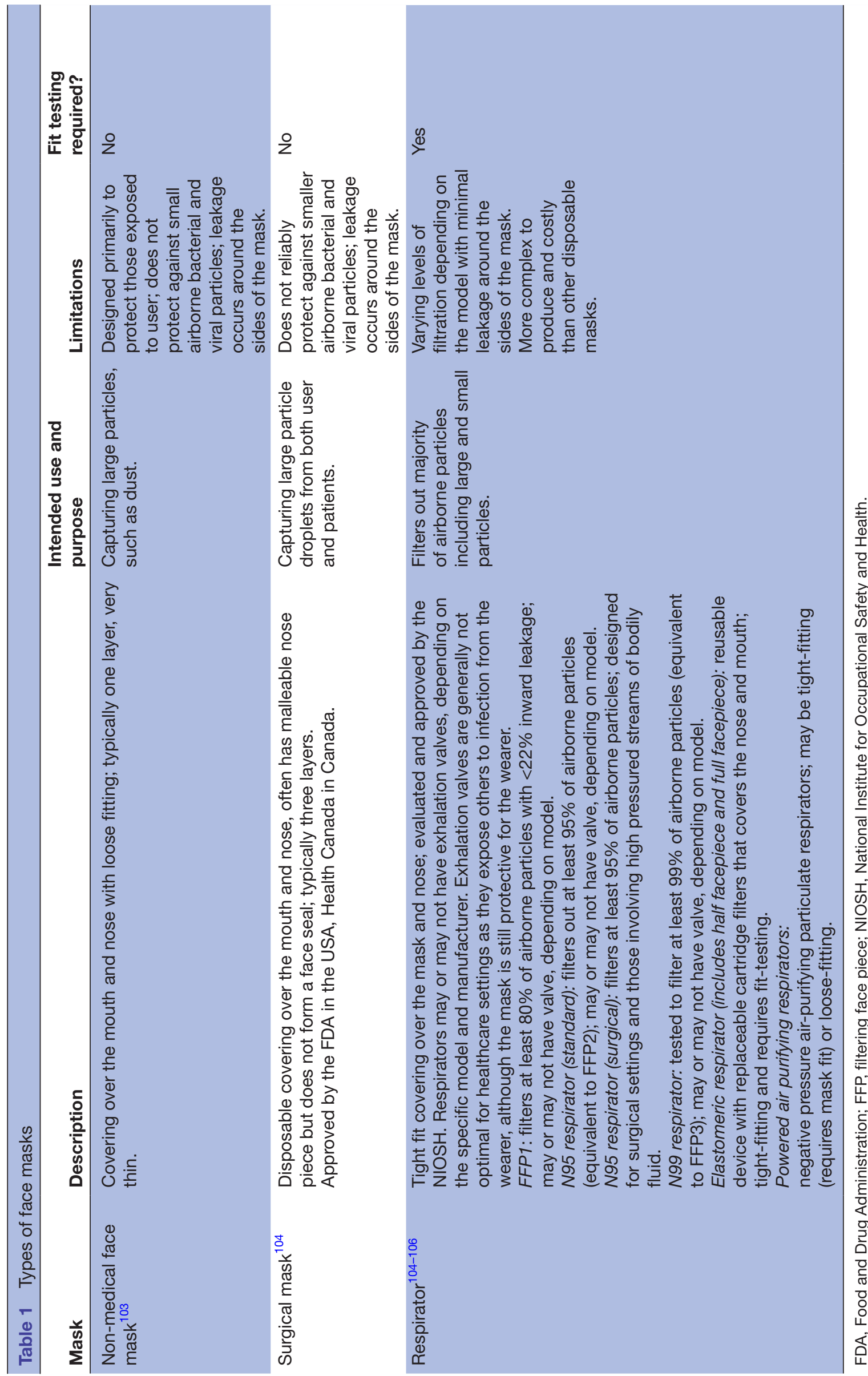


potential organisational methods, reuse of disposable products, non-traditional mask sources and novel approaches for fabrication. ${ }^{15}$ The Journal of the American Medical Association (JAMA) recently issued a Call for Ideas for unconventional pitches related to increasing the PPE supply. ${ }^{16}$ While numerous editorials and news articles address this topic, we are unaware of a systematic search of the published research to date. ${ }^{17} 18$

The objective of this scoping review is to characterise the research outcomes for preclinical and clinical interventions for overcoming limited supply of masks during pandemics and epidemics. We hope to inform best practices for addressing the current and potential future shortage of PPE supply while still maintaining both patient and provider safety.

\section{METHODS}

The scoping review was conducted according to the standards and guidelines established in the Preferred Reporting Items for Systematic Reviews and Meta-Analysis (PRISMA) with the associated extension for Scoping Reviews, in addition to the fourth edition of the Joanna Briggs Institute Reviewer's Manual. ${ }^{19}{ }^{20}$ We registered an iterative protocol through the Open Science Forum. ${ }^{21} 22$ Changes to the protocol were minimal, including one change to the search criteria to broaden the search by adding keyword searches.

\section{Search strategy}

We conducted a systematic literature search of MedlineOVID, EMBASE, CINAHL and Cochrane Library. Databases were examined from 1995 until the date of our literature searches (4 June 2020). The cut-off of 1995 was designated in order to balance relevance to newer mask models and infection control guidelines, while still including major epidemics such as SARS in 2003. A copy of the search strategy is provided in the online supplemental appendix 1 .

To ensure completeness, we also searched the references of our full-text articles, as well as the citing articles via Scopus. We also screened the references of identified relevant reviews.

Non-database sources were systematically searched to examine grey literature as well as to identify further peer-reviewed articles that may have been missed in the search. To identify relevant peer-reviewed articles, we hand-searched GoogleFoam, ${ }^{23}$ COVID-19 Expert, ${ }^{24}$ relevant guidelines, ${ }^{4} 525-29$ preprint databases ${ }^{28} 29$ and specialised evidence collections that were specific to the current COVID-19 pandemic. ${ }^{30-36}$ Sources of grey literature included DuckDuckGo, ${ }^{30}$ Google News, ${ }^{31}$ the JAMA Call to Ideas forum ${ }^{16}$ and LexisNexis. ${ }^{32}$ Details of the grey literature sources are listed in table 2. The sources of grey literature were selected by two frontline clinicians and senior authors (JMB, SMF) on the basis of relevance to the field.
Articles were excluded if they did not report outcomes, were not specific to pandemics or epidemics, did not include English translations or were only relevant for a community setting. Details of the eligibility criteria are provided in box 1 .

\section{Study selection}

Each title/abstract identified from the database search underwent two rounds of screening by two independent reviewers. A total of four independent reviewers (AK, SK, TG, MY) participated in the screening process, with each reviewer reviewing half of the yield. A pilot test of the title/abstract screening was completed among the four reviewers for the first 200 search results to ensure sufficient inter-rater agreement. Afterwards, two reviewers (AK, SK) examined full-texts to assess for eligibility. Any disagreements between the two reviewers was resolved through discussion and consultation with the two senior authors (JMB, SMF).

\section{Data extraction}

To facilitate data extraction, a standardised form was developed and piloted on five studies. The data extraction template was modified in an iterative process until the research team was satisfied with its state. Two reviewers (AK, SK) piloted extraction for five studies with each other for the purpose of improving the extraction process.

Following the pilot, the full data extraction was completed by the four reviewers (AK, SK, TG, MY) working in parallel. Any disagreements in data extraction were resolved through discussion and consultation with the content experts (JMB, SMF). Summary and synthesis were completed descriptively.

\section{Quality assessment and risk of bias}

The quality rating of all studies was also graded in duplicate by two reviewers (AK, SK) using a rating scale adapted from the Oxford Centre for Evidence-based Medicine. ${ }^{37}$

The risk of bias of the included studies was then systematically assessed by at least two independent reviewers (AK, SK, JMB). Non-randomised trials were evaluated using the RoBANS tool, while randomised controlled trials (RCTs) were evaluated using the Cochrane risk of bias tool. To our knowledge, there is no widely accepted measure of quality for preclinical studies. As such, we adapted approaches previously reported in the literature to select five markers of quality for our included preclinical studies. ${ }^{38-42}$

\section{Patient and public involvement}

Patients and members of the public were not involved in the conduction of this scoping review.

However, this review was conducted under the supervision of two academic emergency physicians who serve on the frontlines during the COVID-19 pandemic. The relevance of the research question and outcome measures were thus informed by their priorities, experiences, 1 and preferences as HCWs. 
Table 2 Sources hand-searched for peer-reviewed literature

Source
Evidence collections
- Evidence Aid
- BMC
- NEJM $^{33}$
- Springer
- Lancet $^{36}$
- Elsevier
- BMJ $^{108}$
Google Foam $^{23}$

COVID-19 Expert application ${ }^{24}$

Preprint databases

- Channel: COVID-19 SARS-CoV-2 preprints from medRxiv and bioRxiv ${ }^{28}$

- Open Science Forum: Preprint Archive Search for COVID-19 or 2019-ncov ${ }^{29}$

Published guidelines ${ }^{4525-29}$
CDC recommendations
National Personal Protective Technology Laboratory
Personal Protective Equipment Conformity Assessment
Studies and Evaluations
- JAMA Clinical Guidelines Synopsis
- Public Health Agency of Canada guidelines 29
- Anfection Prevention and Control Canada guidelines ${ }^{28}$
paperican College of Emergency Physicians position
- Canadian Association of Emergency Physician PPE
position paper

\section{Details of source and methodology}

These are curated evidence collections, editorials, guidelines and news pieces available from major publishers and evidence groups.

Collections were hand-searched for all articles until 6 April 2020

BMC, BioMed Central; BMJ, British Medical Journal; CDC, Centers for Disease Control and Prevention; JAMA, Journal of the American Medical Association; NEJM, New England Journal of Medicine; PPE, personal protective equipment.

\section{RESULTS}

\section{Search yield}

Results of the study screening process are available in the PRISMA diagram in figure 1. Of the 11220 imported titles and database citations, 5038 remained after duplicates were removed. After title and abstract screening, 71 were eligible for full-text evaluation. Of the 71 full-text articles, a total of 47 met inclusion criteria for this scoping review.

\section{Article characteristics}

Full details of the included articles are available in the online supplemental appendix 2.

All 47 studies were full-text articles. Of the 47 studies, 27 were laboratory-based. The remainder were user acceptance studies $(n=5)$ or clinical designs $(n=15)$. Of
Google Foam is a search engine of Free Open Access Medical Education, including blogs, podcasts, journal articles and social media posts.

Google Foam was searched for relevant articles until 8 April 2020.

This is a digital application that is used by clinicians, which collects articles, guidelines and hospital policies related to COVID-19.

COVID-19 Expert application was searched for relevant articles until 8 April 2020.

Preprint databases are advanced sharing platforms to provide open access to articles prior to publication. Their articles are not yet peer reviewed.

The references from the first 100 articles on each preprint database were hand-searched to identify relevant peer-reviewed articles on 8 April 2020.

These guidelines include clinical care guidelines for patients with COVID-19, position papers on PPE as well as recommendations for extended use and limited reuse of N95 filtering facepiece respirators in healthcare settings.

The references from the cited guidelines were hand-searched to identify relevant peer-reviewed articles. 


\section{Box 1 Eligibility criteria}

Population:

Relevant to healthcare providers/hospital staff/medical institutions/ long-term care homes/dental offices/paramedics and prehospital care workers/military medical services/refugee health workers or any medical institutions that use face masks for medical purposes. Face masks include surgical masks and non-powered respirators.

\section{Intervention:}

Any intervention with the purpose of conserving/rationing masks relevant to pandemics/epidemics; any intervention with the purpose of increasing the supply of masks through procurement from other sources relevant to pandemics/epidemics.

\section{Comparator:}

Not available (any identified from literature).

\section{Outcomes:}

Any outcome reported in the literature (can be qualitative or quantitative, may include patient outcomes/provider outcomes, may include increases to supply, may include other markers of clinical quality of performance).

and one did not include any statement of potential conflicts of interest. The remaining 24 studies did not provide a disclosure statement.

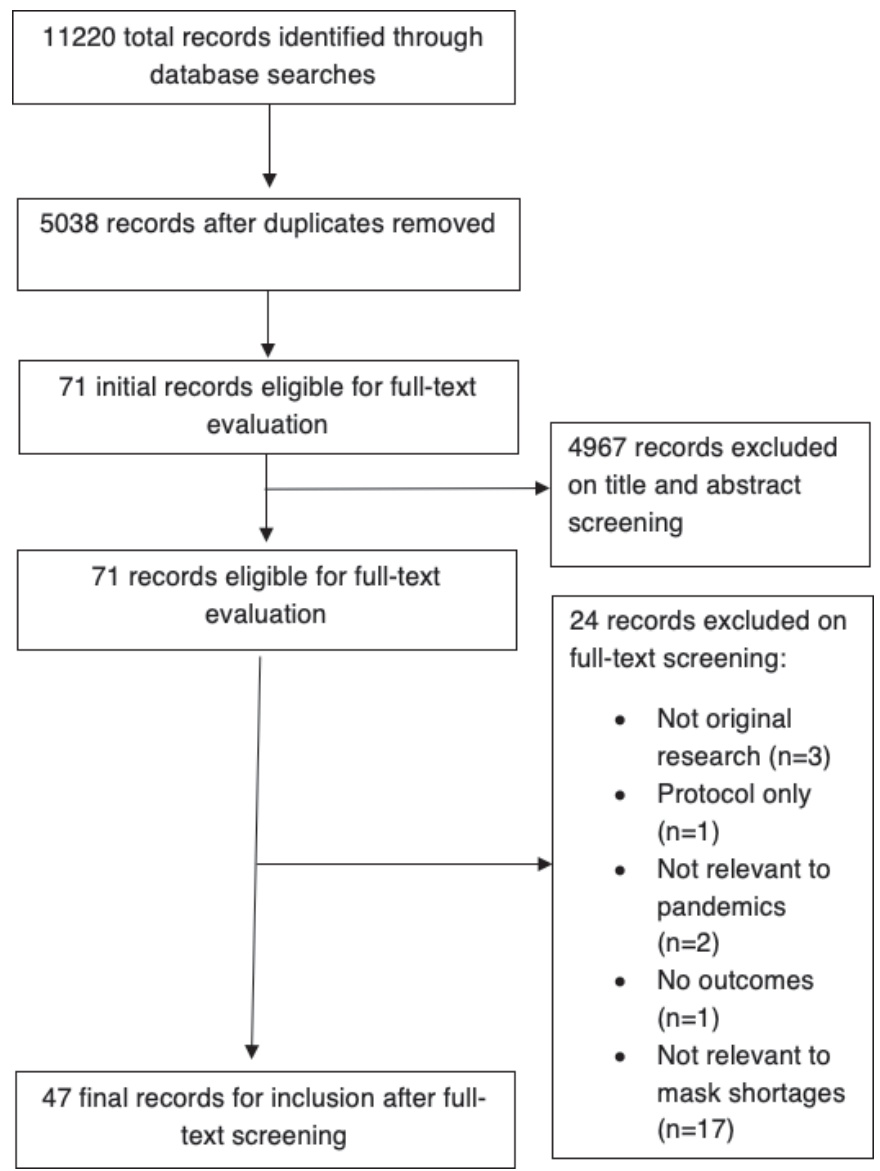

Figure 1 Preferred Reporting Items for Systematic Reviews and Meta-Analysis diagram.

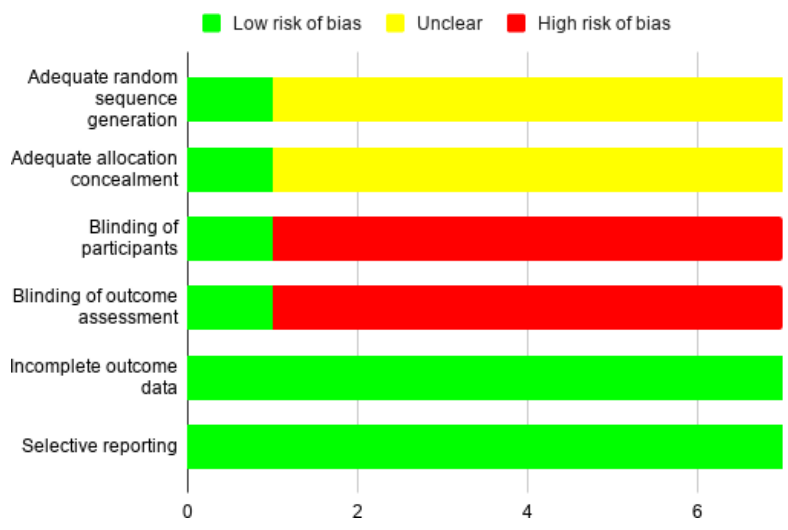

Figure 2 Cochrane risk of bias tool. Seven randomised controlled trials were evaluated using the Cochrane risk of bias tool. The majority $(n=6)$ were noted to be intermediate risk, with one study graded as low risk.

Details of the evidence grading and risk of bias assessment are available in the online supplemental appendix 2 as well as in figures $2-4$.

\section{Strategies for overcoming limited supply}

The research literature revealed numerous strategies evaluated for overcoming a limited supply of PPE during pandemics or epidemics. These strategies can be grouped into six main categories (table 3): decontamination of disposable masks, reuse and/or extended wear of disposable masks, layering of masks, introduction of reusable respirators, use of non-traditional replacements or modifications to masks, and use of stockpiled or expired masks.

\section{Decontamination of disposable masks}

Eighteen of the included studies evaluated decontamination methods of disposable masks in order to facilitate reuse. There were multiple methods of decontamination including: ultraviolet (UV) germicidal irradiation, pasteurisation, dry heat and chemical disinfectants (including ethylene oxide, ammonia, hydrogen peroxide, bleach, isopropyl alcohol, mixed disinfectants and commercially available cleaning wipes). A full summary

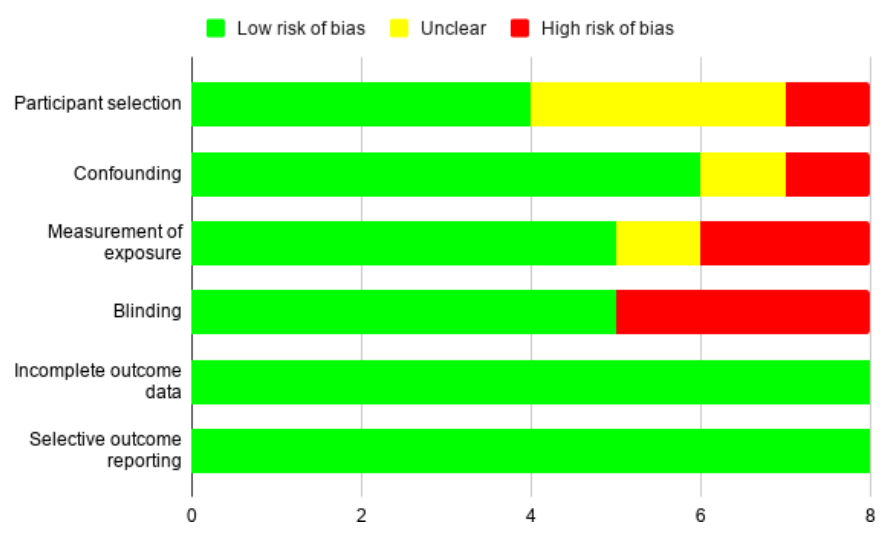

Figure 3 RoBANS risk of bias tool. Eight non-randomised studies were evaluated with the RoBANS tool. Seven studies were graded as low risk, with one study graded as intermediate risk to high risk. 


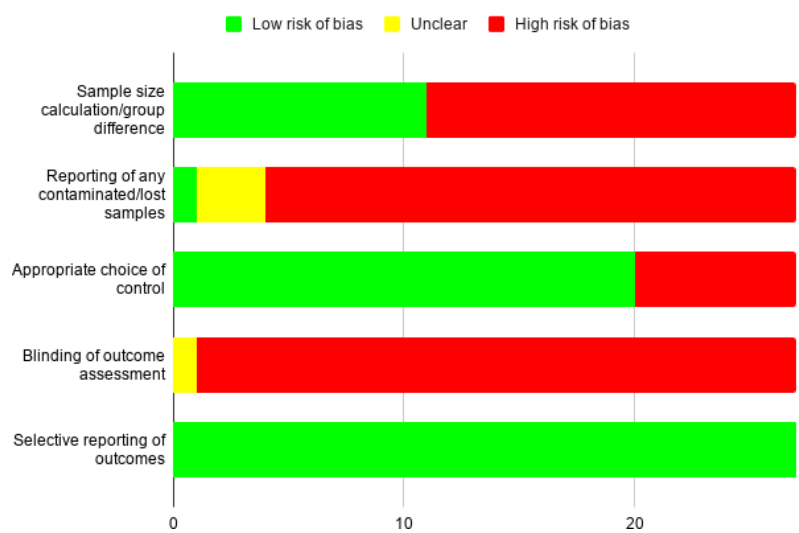

Figure 4 Preclinical risk of bias grading. Twenty-seven preclinical studies were evaluated using markers previously described in literature (see 'Methods' section). All studies were ranked as medium to high risk for bias.

of decontamination methods and assessment using the Health Canada criteria for mask decontamination is included in table $4 .{ }^{46}$

Studies of mask decontamination incorporated one or more of four outcome measures: (1) decontamination efficacy, (2) filtration performance after decontamination, (3) complications of decontamination, (4) user experience/acceptance of decontamination. Fifteen studies evaluated the efficacy of methods for decontamination of filtering facepiece respirators, including N95s and P100s. These were conducted in controlled laboratory settings, where primary outcomes included changes in viability of live pathogens and filtration performance on decontamination. Evaluated pathogens included strains of H1N1 (n=3), MS2 bacteriophage $(\mathrm{n}=4)$, Escherichia coli $(\mathrm{n}=1)$, Bacillus subtilis $(\mathrm{n}=1)$, Geobacillus stearothermophilus $(\mathrm{n}=1)$ and Staphylococcus aureus $(\mathrm{n}=1) \cdot{ }^{47-51}$ All studies noted some degree of reduced virus viability with UV, chemical or heat-based decontamination methods. The most studied method of decontamination was UV radiation, with 13 studies evaluating either UVA or UVC radiation at varying doses and exposure times (details in table 5). While most studies found most decontamination methods to be effective, UVC radiation (15 W $254 \mathrm{~nm}$ bulbs for $15 \mathrm{~min}$ ) was noted as the most effective method by Lore et $a l^{\tilde{D}^{0}}$ in comparison to microwave-generated steam or moist heat. In addition, decontamination using non-medical commercially available wipes and ethanol was notably ineffective. ${ }^{52}{ }^{53}$ In the only available comparison of UVC and UVA, UVA was found ineffective compared with UVC. ${ }^{53}$

There were contrasting results regarding filtration performance and decontamination methods. Several

\section{Table 3 Description of strategies}

\section{Strategies \\ Description of methods}

(1) Decontamination of disposable masks ${ }^{47-50}$ 52-56 59-62 109-111

(2) Reuse of disposable masks ${ }^{63-65} 70-72$

(3) Extended wear of disposable masks $^{63-72}$

(4) Layering of masks ${ }^{69} 73-76$

(5) Reusable respirators ${ }^{77-83}$

(6) Unconventional mask replacements or modifications ${ }^{43-4584}$

(7) Stockpiled or expired masks $s^{57} 85-87$ different types of masks. equipment as masks.
Sterilisation or cleaning of masks in order to reuse masks that are typically meant to be disposed of after use. Methods of decontamination included ultraviolet germicidal irradiation, pasteurisation, dry heat and chemical disinfectants (including ethylene oxide, ammonia, hydrogen peroxide, bleach, isopropyl alcohol, mixed disinfectants, cleaning wipes, see table 4).

Reuse of disposable masks without decontamination or disinfection.

Use of disposable masks for longer than standard practice.

\section{Evaluatingstudies}

Fisher et al, ${ }^{47}$ Fisher and Shaffer, ${ }^{109}$ Heimbuch et al, ${ }^{52}$ Lin et al, ${ }^{54}$ Mills et al, ${ }^{48}$ Nemeth et $a l,{ }^{61}$ Bergman et al, ${ }^{56}$ Lin et al, ${ }^{53}$ Lindsley et al, ${ }^{60}$ Lore et $a l,{ }^{50}$ Richter et al, ${ }^{51}$ Salter et al, ${ }^{55}$ Viscusi et al, ${ }^{55}$ Viscusi et $a l,{ }^{57}$ Viscusi et $a l,{ }^{62}$ Vo et $a l,{ }^{111}$ Woo et $a l,{ }^{110}$ Heimbuch et $a l^{49}$

Bergman et al, ${ }^{70}$ Coulliette et al, ${ }^{63}$ Fisher et $a l,{ }^{64}$ Fisher et al, ${ }^{65}$ Pillai et al, ${ }^{72}$ Vuma et $a l^{71}$

Bergman et al, ${ }^{70}$ Brady et al, ${ }^{67}$ Coulliette et al, ${ }^{63}$ Duarte et al, ${ }^{66}$ Fisher et al, ${ }^{64}$ Fisher et al, ${ }^{65}$ Pillai et al, ${ }^{72}$ Radonovich et al, ${ }^{68}$ Shenal et al, ${ }^{69}$ Vuma et al ${ }^{71}$

Layering of multiple masks or overlay of Derrick et al, ${ }^{73}$ Rebmann et al, ${ }^{74}$ Roberge

Fabrication or testing of reusable respirators that are meant to be decontaminated between uses.

Assessment of cloth masks, new mask types, modifications of existing mask designs and use of non-medical

Use of masks in long-term storage or stockpile facilities, potentially after expiry date. 


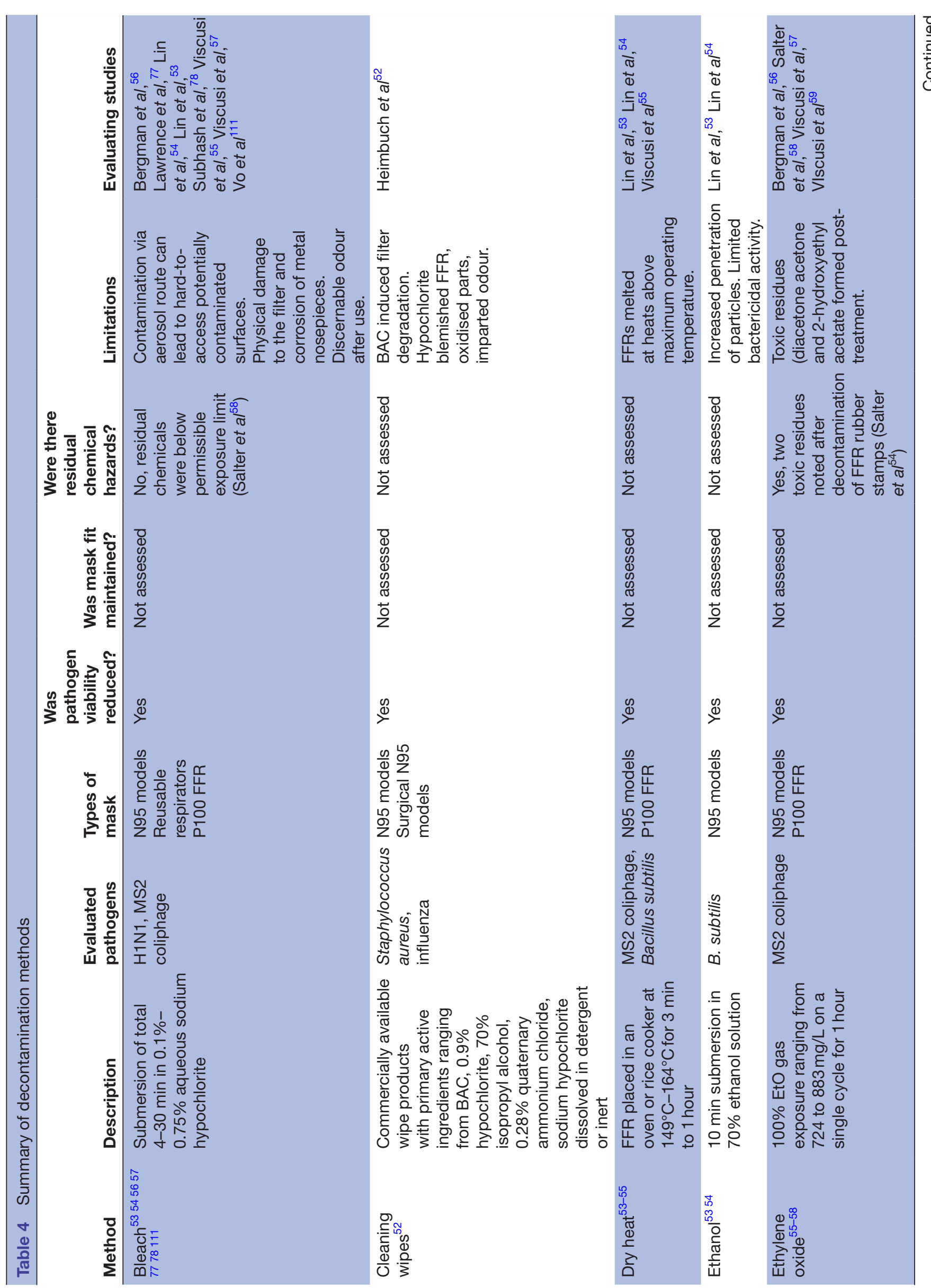




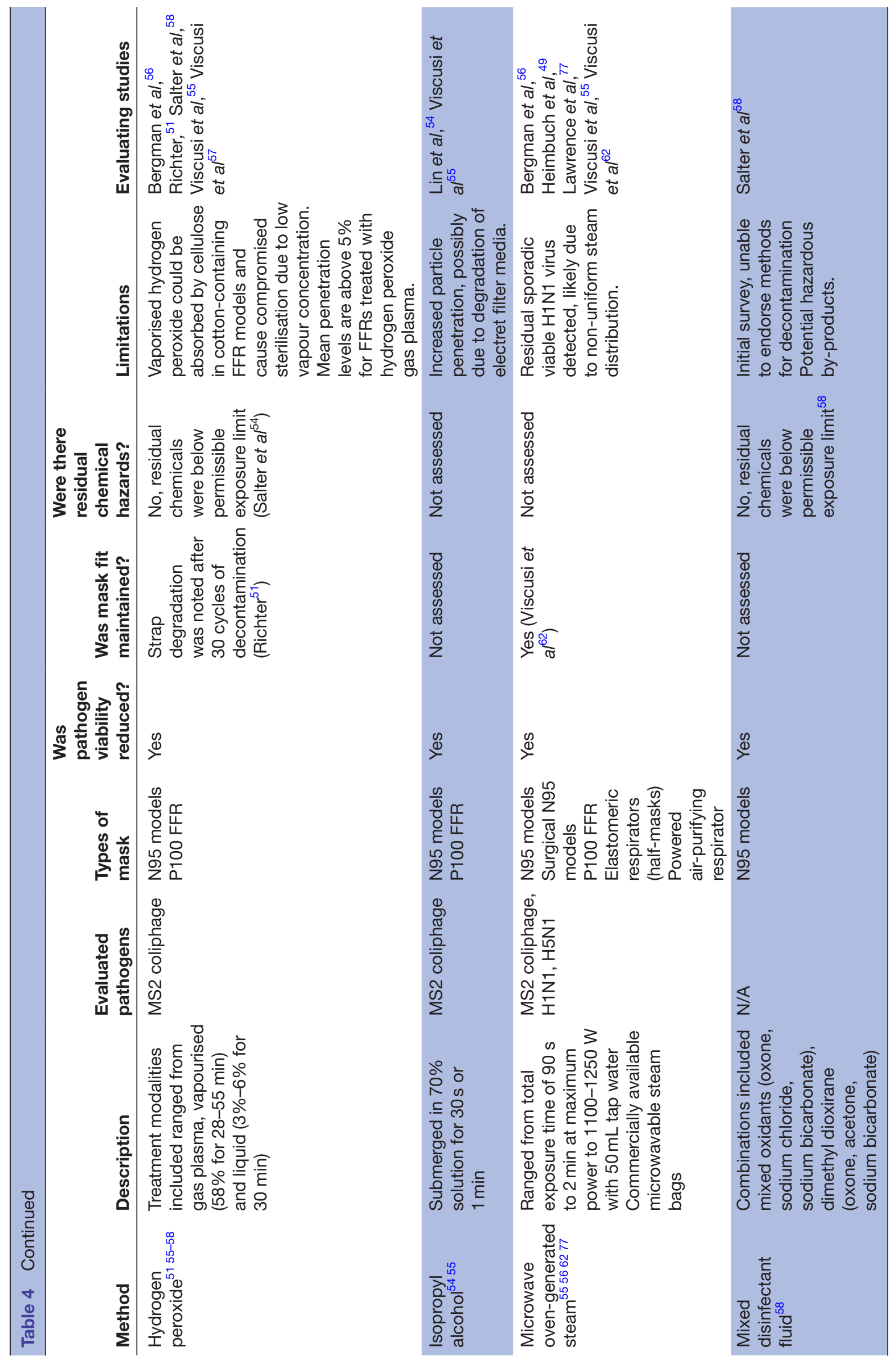




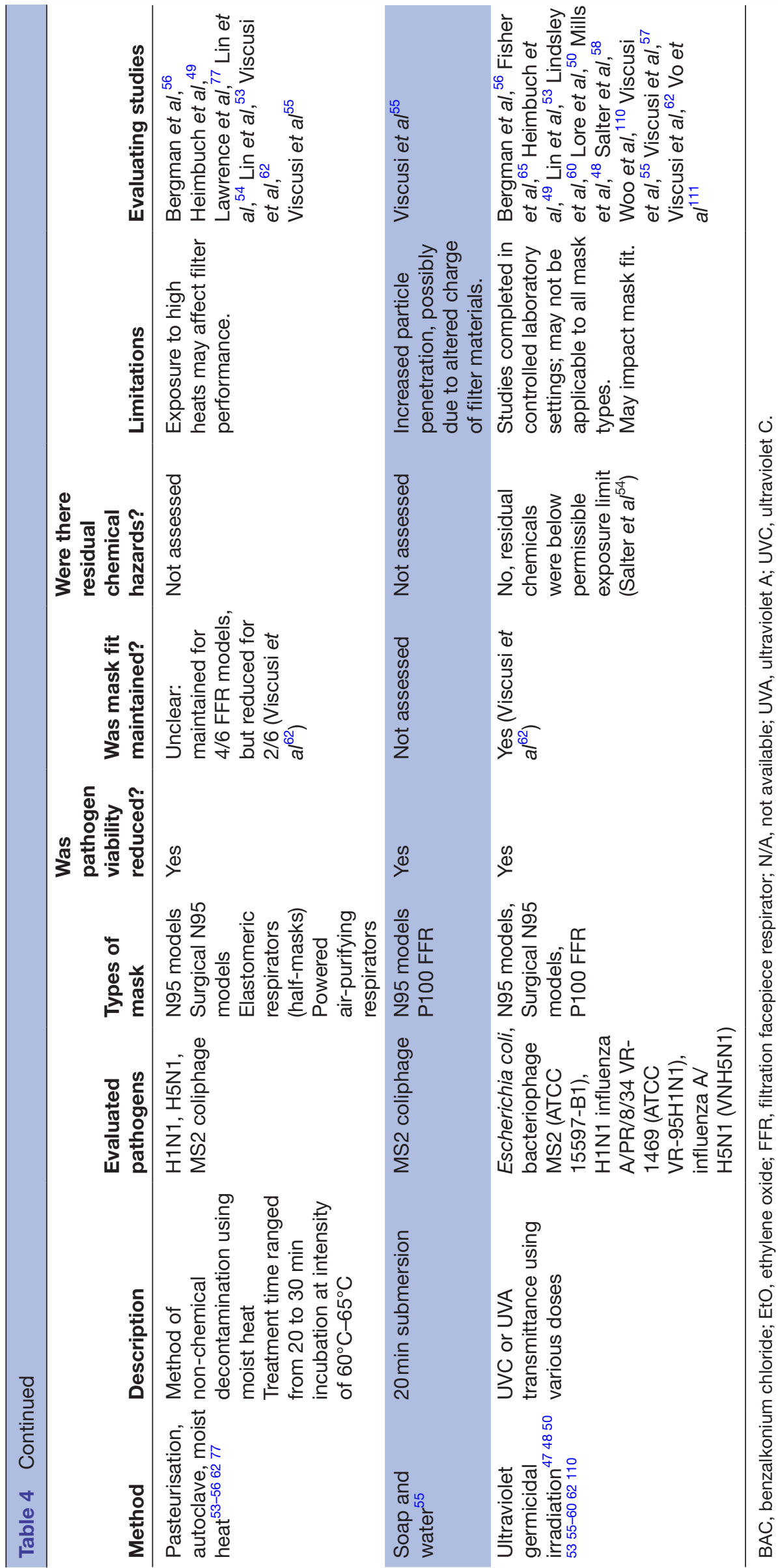




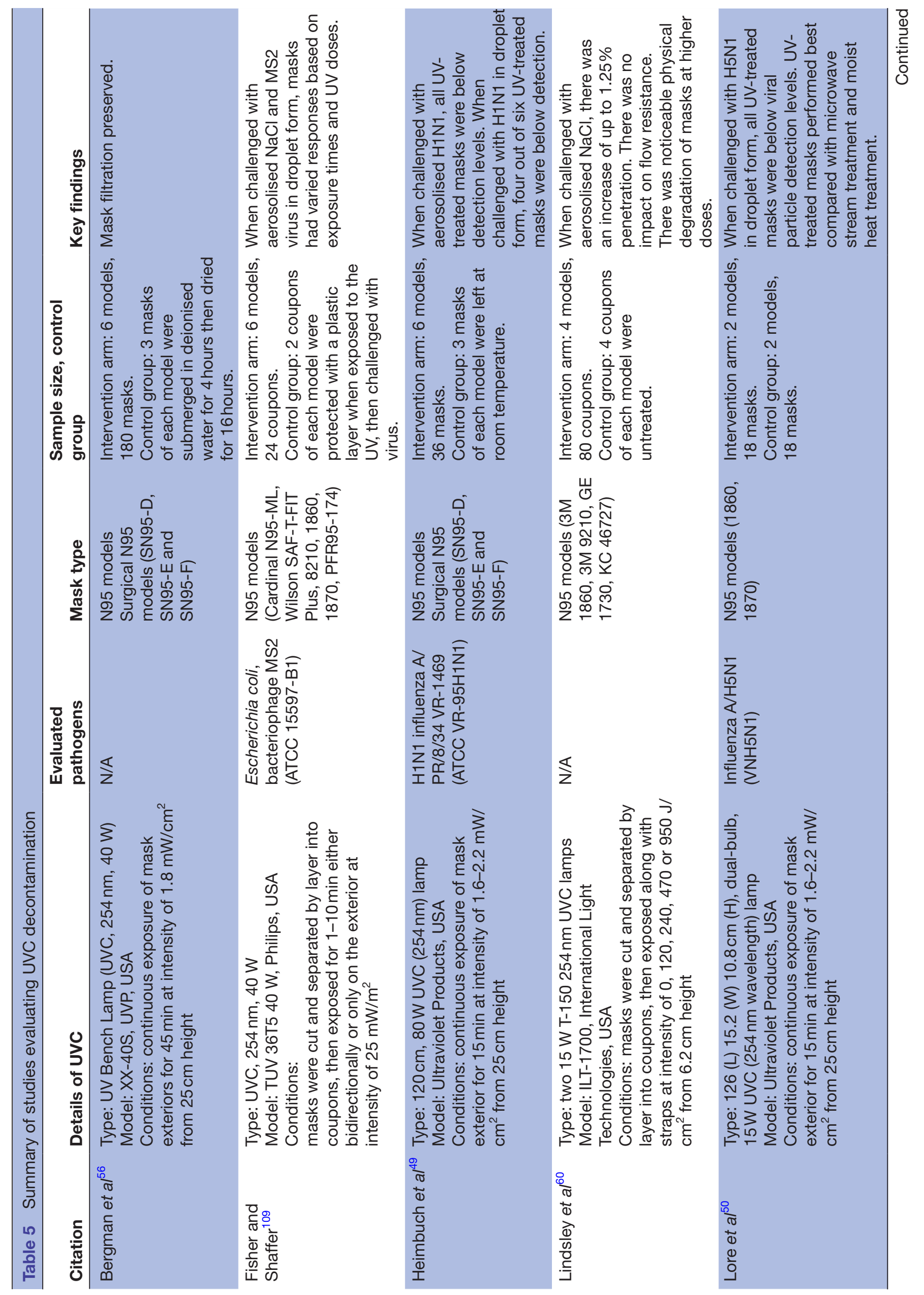



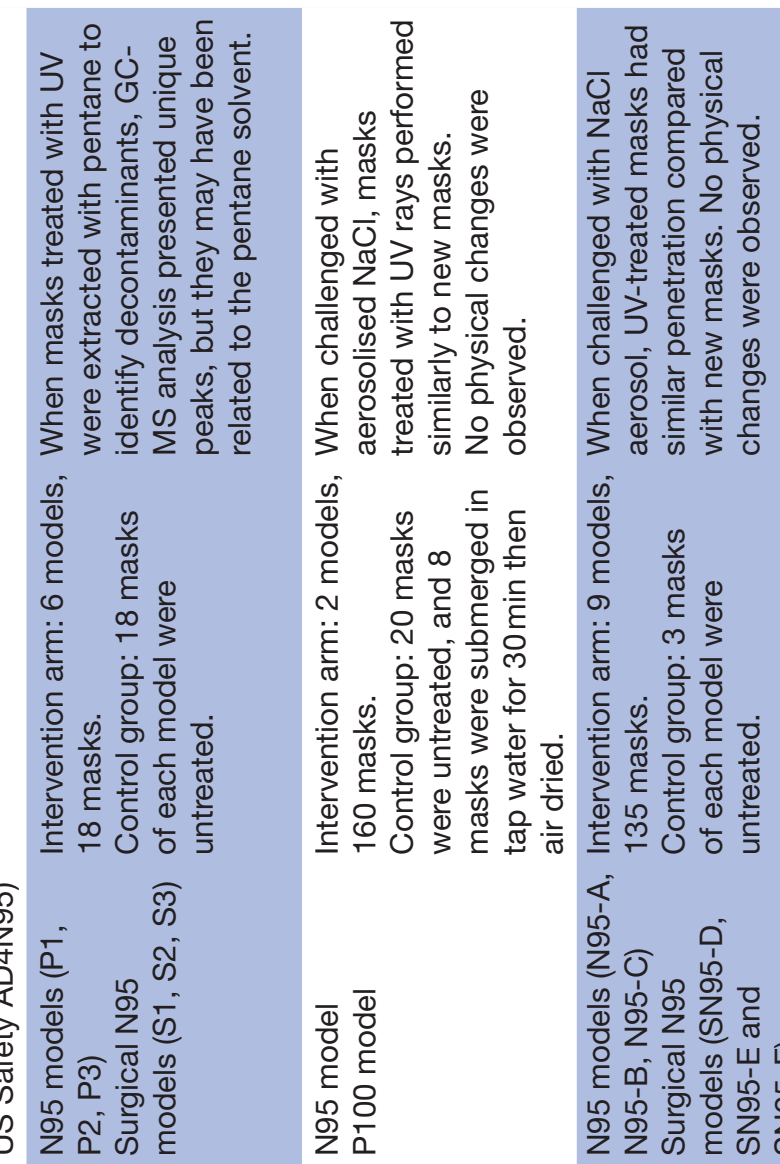

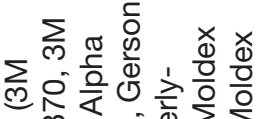

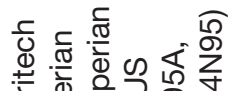

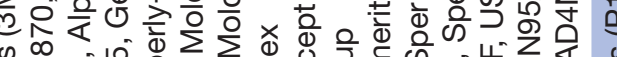

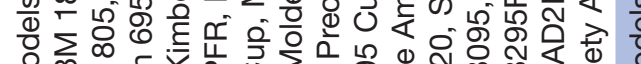
m

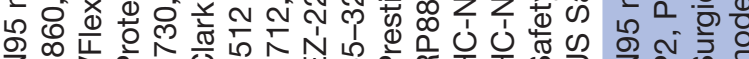

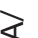

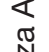

$\stackrel{\frac{1}{5}}{\frac{1}{4}}$

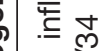

立 $\frac{\infty}{q}$

g

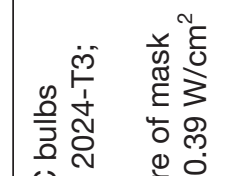

ऐo

ह 을

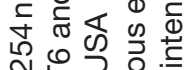

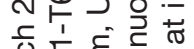

गे

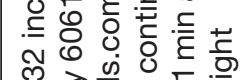

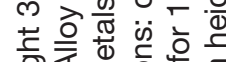

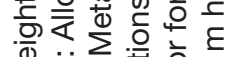

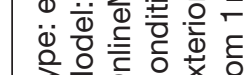

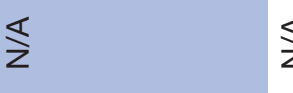

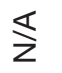

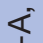
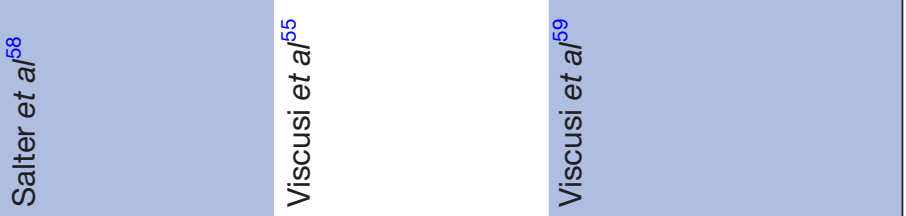


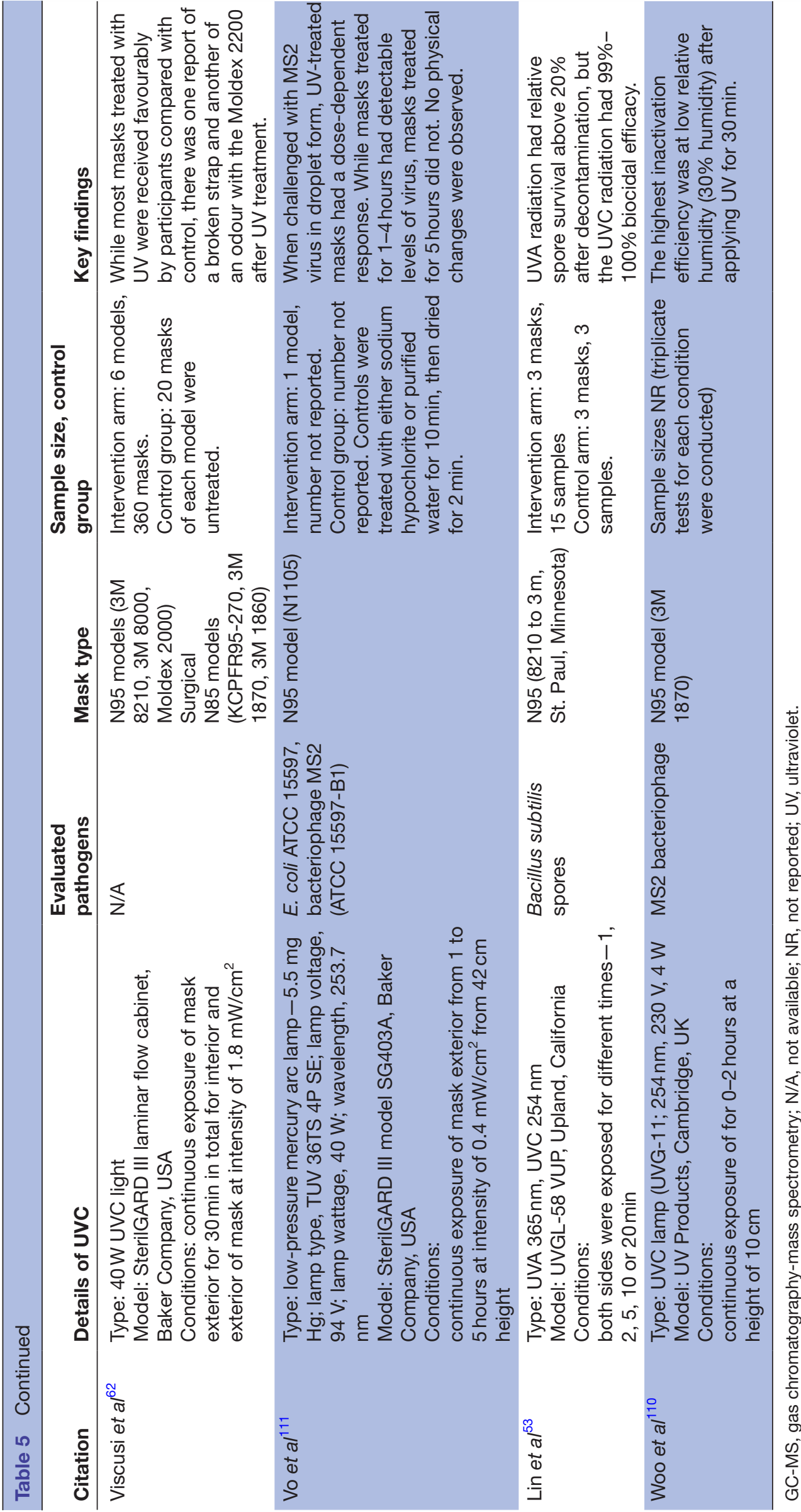


studies found diminished filtration performance on decontamination with bleach, ethylene oxide, ethanol, autoclaves, rice cookers or microwave heat. ${ }^{5254}$ Viscusi et $a \bar{l}^{5}$ found that UV and hydrogen peroxide (liquid and vaporised) had the least effect on filter performance. However, Bergman et $a l^{56}$ found that, with the exception of hydrogen peroxide gas plasma which performed poorly, all treatment and control groups had comparable impact on filtration performance. Similarly, Fisher et al noted that microwave steam bags were $99.9 \%$ effective in MS2 decontamination while maintaining filtration efficiency. ${ }^{47}$

There were several complications associated with decontamination. For example, microwave irradiation using dry heat was noted to melt several filtration facepiece respirator (FFR) models. ${ }^{547}$ Decontamination using ethylene oxide created hazardous by-products that could be injurious to provider. ${ }^{58}$ Bleach would often impart a discernible odour on the FFR as well as corrode metal parts, such as the nose clip of masks. ${ }^{58}$ Physical degradation also occurred in a dose-dependent manner with UV treatment and after repeated hydrogen peroxide treatment. ${ }^{5160}$ However, most studies did not formally assess mask fit after decontamination (table 4).

Two studies analysed the determinants related to provider uptake of decontamination. ${ }^{6162}$ Nemeth $e t a b^{61}$ evaluated user acceptance of FFR decontamination, noting that perceived safety of UV decontamination was higher in comparison to wearing an FFR for an extended period of time without decontamination. ${ }^{61}$ Viscusi et a ${ }^{62}$ reported that decontamination with UV, moist heat or microwave steam did not significantly change the user experience. Their clinical study found that FFR users are not likely to experience clinically meaningful reduction in fit, or an increase in odour, discomfort or difficulty in donning after decontamination. However, the authors noted that their results may have limited generalisability, as participants only wore the masks for $30 \mathrm{~min}$ when assessing comfort.

\section{Reusability and extended wear of disposable masks}

Ten studies evaluated outcomes related to the reusability and extended wear of disposable masks. All 10 studies evaluated N95 respirators, while 2 studies additionally evaluated surgical masks. Details of the studies are provided in table 6 .

Three studies were laboratory-based. ${ }^{63-65}$ Coulliette et $a l^{63}$ noted that H1N1 viruses remained infectious for 6 days when deposited on the respirators under several conditions. Similarly, Fisher $e t a b^{64}$ found that respirators have the potential to act as fomites, as MS2 bacteriophage were still detectable on the 10th day after deposition. Another study considered contamination with extended use, by quantifying the reaerosolisation of MS2 bacteriophage due to reverse airflow after simulated coughing. They found that $<1 \%$ of viable virus was reaerosolised after a single cough.
Of the six clinical studies, two examined the performance of N95s after extended use in a healthcare setting. Duarte $e t$ al assessed the physical damage of N95 respirators over 1-30 days of consecutive use. ${ }^{66} \mathrm{~A}$ total of 668 respirators worn by 167 nursing assistants were evaluated. Past the fifth day of consecutive use, the respirators were visibly contaminated and folded. However, this was a subjective assessment of mask damage and was limited to visual characteristics. In contrast, Brady et $a l^{67}$ presented a more controlled clinical study that assessed pathogen transfer after reuse of N95s. Their results found that adequate doffing procedures had a greater impact in preventing contamination than whether a mask was reused. Specifically, MS2 bacteriophage contamination was lower with reuse and proper doffing in comparison to improper doffing.

Two studies analysed perceived discomfort and exertion of HCWs on extended wear of the masks. Radonovich $e t$ $a b^{68}$ noted that participants discontinued N95 use before 8 hours in $59 \%$ of sessions, citing intolerance. Similarly, Shenal et $a l^{69}$ noted that perceived discomfort increased over an 8-hour period, but exertion only marginally increased. In addition, two studies noted that fit testing scores of respirators dropped significantly with multiple wears. Specifically, fit factor consistently dropped after a maximum of five consecutive donnings and half of participants failed at least one fit test after repeated donning and doffing. ${ }^{70} 71$

Finally, Pillai et $a l^{2}$ conducted a survey of physician preferences regarding conservation strategies in N95 shortages. They noted that extended and reuse of disposable N95s was the most preferred conservation strategy, in comparison to use of reusable respirators. ${ }^{72}$

\section{Layering of multiple masks}

Five studies evaluated outcomes related to layering multiple masks, including layering the same mask type $(n=1)$ versus overlay of one mask model over another $(n=4)$. Details of the included studies are outlined in table 7 .

Derrick $e t a l^{73}$ evaluated combinations of one, two, three or five surgical masks overlayed on top of one another in a crossover study of six volunteers. They noted that while combining multiple surgical masks improved filtration, this was still well below that of $\mathrm{N} 95$ respirators. ${ }^{73}$

Three clinical studies evaluated user experience of surgical mask overlay over N95s. ${ }^{69} 7475$ Shenal $e t a l^{69}$ and Roberge $e t a l^{75}$ found no statistically significant differences between overlay versus N95 respirator on its own. In contrast, Rebmann $e t a l^{74}$ found that the overlay was perceived to be less comfortable and raised $\mathrm{CO}_{2}$ levels significantly, but without clinically relevant outcomes. ${ }^{74}$

Finally, a laboratory study found that the effect of a surgical mask overlay had variable effects depending on the model of N95. ${ }^{76}$ For cup models, this worsened respiratory gases, but for horizontal models it improved or did not change these values. The authors suggested that the 


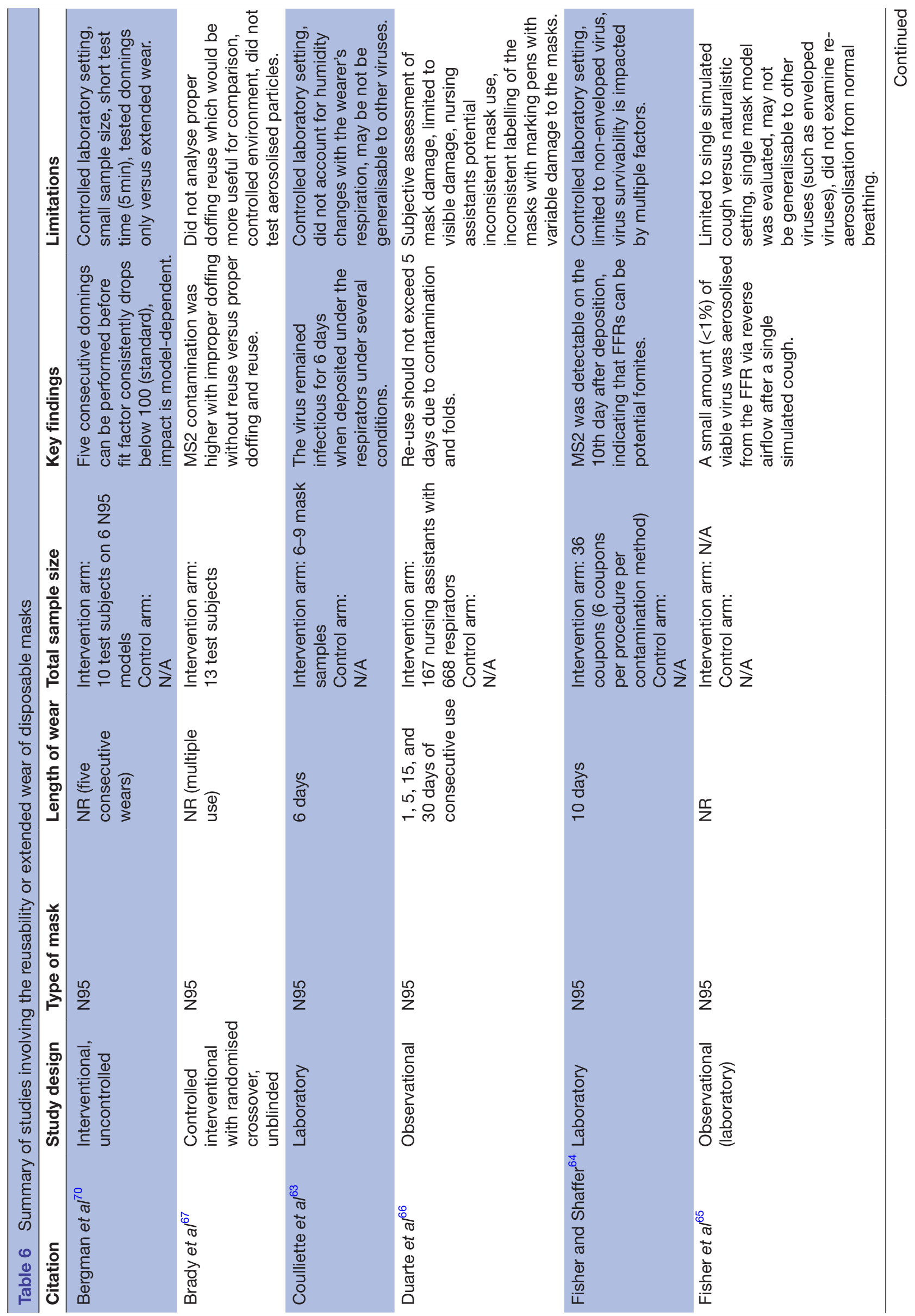




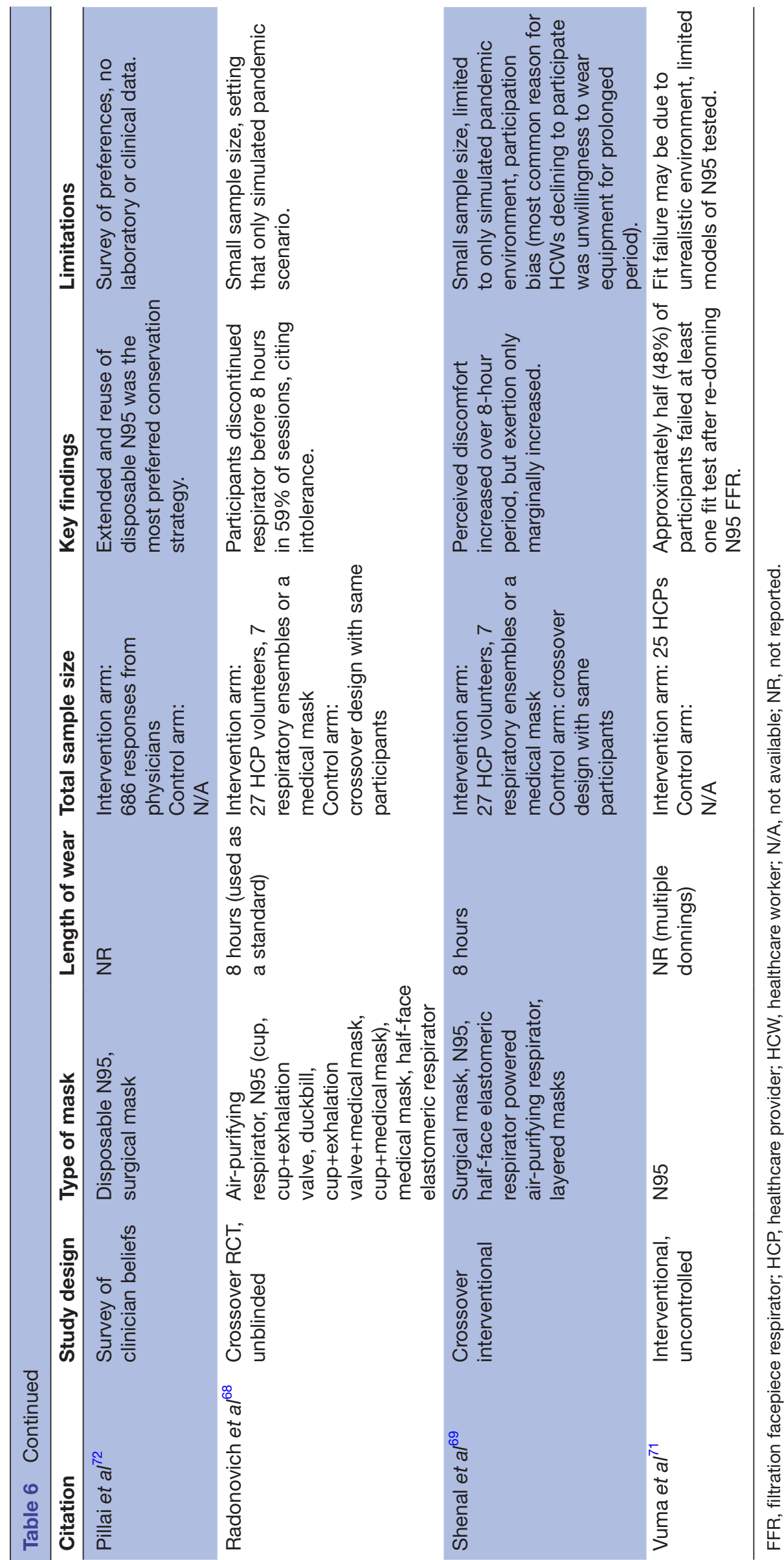




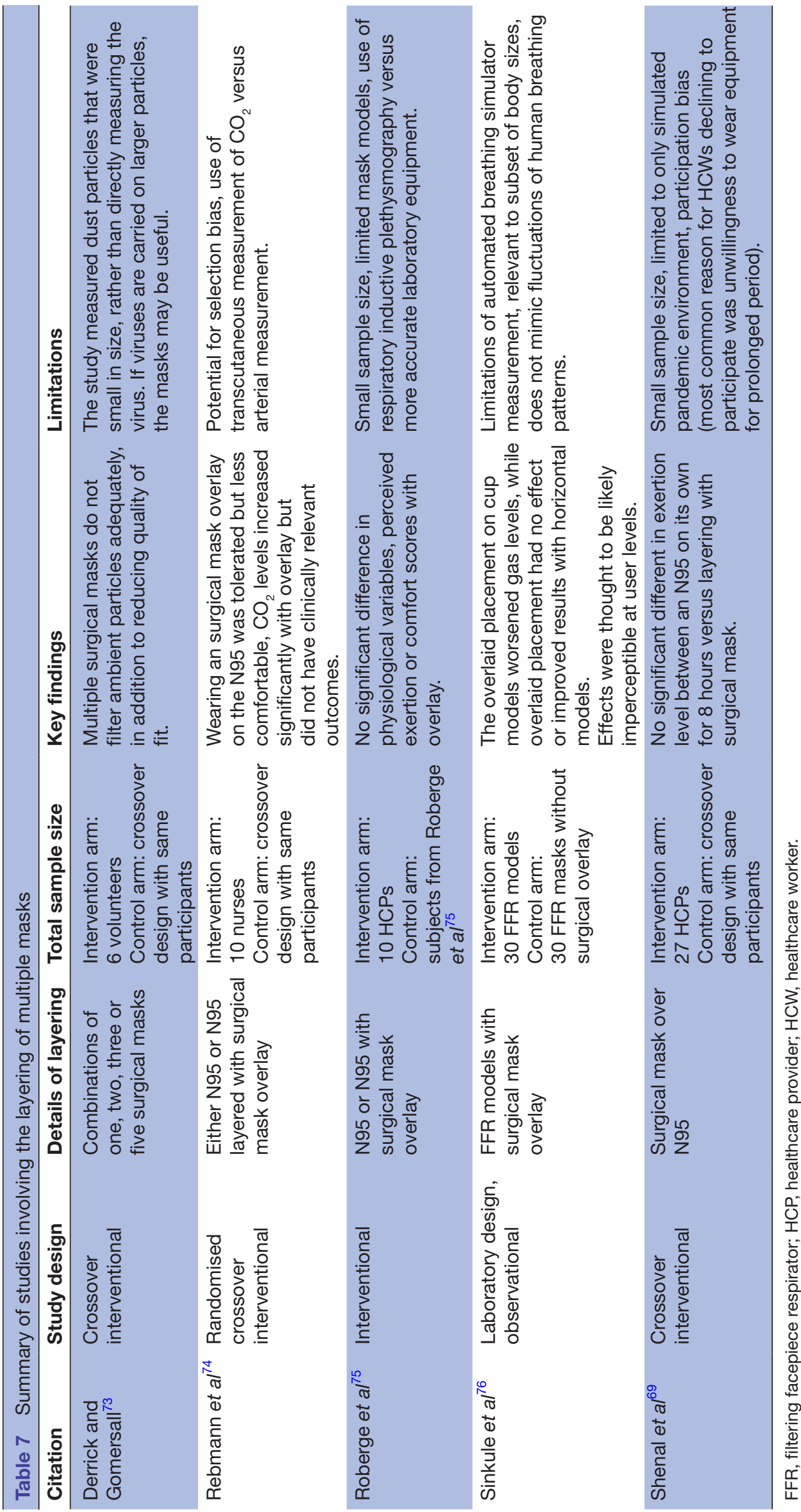


differences would likely be imperceptible at low levels of exertion, however, no clinical correlates were evaluated.

\section{Introduction of reusable respirators}

Seven studies evaluated the use of reusable respirators as a method of conservation for disposable masks (table 8).

Two laboratory-based studies evaluated the efficacy of decontamination of reusable respirators. ${ }^{77} 78$ Both studies reported that chemical disinfectant wipes (combined isopropyl alcohol plus quaternary ammonium wipes) were effective against influenza, but Subhash $e t a l^{78}$ found that isopropyl alcohol alone was ineffective.

The remaining five studies analysed the logistics and feasibility of introducing reusable respirators. Bessesen $e t$ $a l^{99}$ noted that creation of standard operating procedures for disinfection significantly reduced the number of errors made by HCW, in comparison to following manufacturer instructions. ${ }^{79}$ In addition, Pompeii $e t a \ell^{80}$ found that HCWs can be rapidly fit tested and trained to use the reusable elastomers in an outbreak simulation. Reusable elastomers did not require significantly different fit times in comparison to N95 fit testing.

Finally, three studies by Hines $e t a l^{81-83}$ evaluated user preferences and driving factors behind reusable elastomer programmes via surveys, focus groups and interviews. Reasons for adoption included perception that elastomers are more protective and useful during N95 shortages. Concerns for adoption included lack of convenience, dissatisfaction with breathing when wearing the respirator and obstacles to access disinfection services. Other barriers to compliance and continued use were lack of availability, difficulties with storage, and difficulties changing filters.

\section{Unconventional mask replacements or modifications}

Three studies evaluated non-traditional reusable masks ${ }^{43-45}$ (table 9). Au et al ${ }^{45}$ tested a reusable plastic mask trimmed to the user's face via an unblinded RCT. They noted that N95s were more effective in reducing airborne particles than the reusable masks. Two studies evaluated reusable cloth masks. MacIntyre $e t a t^{43}$ conducted a multiinstitute RCT in a low-resource setting, in which reusable cloth masks were provided to 569 HCWs. Five double-layer cotton masks were provided to each worker for the four consecutive weeks, to be washed with soap and water each day. The rate of wearer respiratory infection was significantly higher in the cloth mask arm versus the medical mask controls, with laboratory tests also noting higher penetration of particles through the cloth masks. Similarly, Rengasamy et $a l^{44}$ conducted a laboratory investigation in which cloth masks made from sweatshirts, T-shirts, towels, scarves and cotton were evaluated. They noted a wide variation in penetration across different fabrics, with higher penetration in cloth masks versus N95 controls. ${ }^{44}$

Another preclinical study evaluated the creation of a reusable virus deactivation system built into surgical masks. The investigators coated the middle of the threelayer masks (the polypropylene microfiber filter layer) with a solution of $29.03 \mathrm{wt}$ by volume\% of $\mathrm{NaCl} .{ }^{84}$ They noted that salt-coated filters had higher filtration efficiency against influenza viruses, in comparison to bare filters. Mice who were protected against H1N1 by salt filters showed higher survival rate in comparison to mice who were unprotected. The authors additionally noted that the salt-coated filters were effective in a variety of storage conditions.

\section{Stockpiled or expired masks}

Four studies evaluated the performance of respirators after stockpiling or storage (table 10). All four studies had favourable results in quality testing of stockpiled masks.

Greenawald et $a l^{85}$ evaluated almost 4000 masks at 10 stockpile facilities in the USA with varying humidity and temperature parameters. All masks were tested beyond their listed expiration date, which ranged from over 5 to 10 years old. They found that $98 \%$ of tested N95s met performance standards for filtration performance, with only $2 \%$ of respirators having visual inspection concerns. Similarly, Viscusi et $a l^{\tilde{p}^{7}}$ determined that most models stored for up to 10 years in warehouses had adequate filtration performances.

Bergman $e t a l^{86}$ found that the majority of respirator models in storage had adequate fit for subjects. However, Rottach $e t a l^{87}$ found that strap strength across time of storage was model-dependent. While one model showed no clear difference with age, another manufacturer's strap decreased in tensile strength over time.

\section{Summary of grey literature}

There were numerous diverse suggestions in the grey literature for potential conservation strategies. However, we found no included evaluations or outcomes, and no peer-reviewed studies that had not already been captured in our review. Examples of the conservation strategies are listed in table 11.

\section{DISCUSSION}

We included 47 studies in our systematic scoping review to characterise interventions related to overcoming limited supply of masks during pandemics and epidemics. These studies encompassed six broad categories of conservation strategies: decontamination, reusability of disposable masks and/or extended wear, layering, reusable respirators, non-traditional replacements or modifications and stockpiled masks.

Almost half of the included studies were laboratorybased or preclinical, while the remainder were user acceptance studies or clinical designs. A number of promising strategies were identified, including the use of reusable respirators, extended wear of N95s, use of masks stockpiled beyond manufacturer's listed expiry date and decontamination. While numerous studies suggested that decontamination of masks is feasible, there were three potential caveats that require further study: (1) hazardous by-products, (2) physical degradation and (3) 


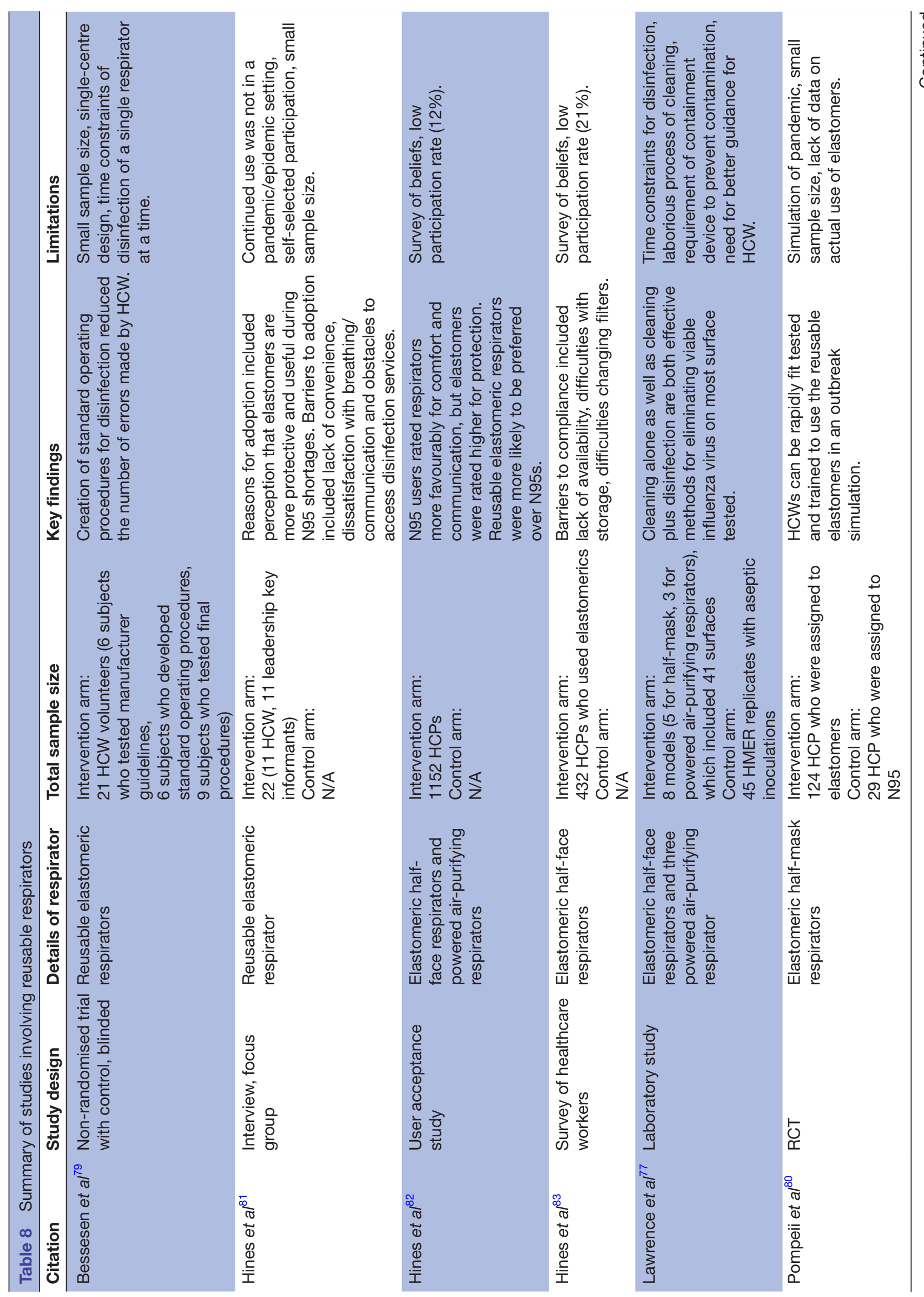


compromise of mask fit. Strategies that were found to be less effective included the use of cloth masks, layering multiple surgical masks or re-donning previously used masks that have not been sterilised. Barriers to mask conservation strategies included the time costs, necessary training and provider compliance. Strategies such as the creation of standardised operating procedures, physician education and user feedback were proposed to overcome these barriers.

However, the generalisability of these findings is limited. Minimum evidence requirements from regulatory agencies such as Health Canada include: demonstration that number of pathogens has been reduced, demonstration that respirator filter and fit performance are maintained, evidence that there is no residual chemical hazard and assurance of adequate labelling. ${ }^{46}$ The available literature does not meet these standards given the relative paucity of clinical studies. Many of the preclinical studies did not evaluate practical logistical barriers towards usage. For example, many studies cut N95 respirators into smaller coupons in order to test various decontamination techniques, precluding any understanding of how masks would perform in a clinical setting in terms of fit and seal, and whether elastic straps or nose bridge would be damaged or decontaminated. Most decontamination studies did not assess mask fit. There were no decontamination studies that evaluated clinical outcomes, such as rate of infection among healthcare providers. In addition, even the more promising approaches remain theoretical, as none of the preclinical studies tested decontamination for the SARS-CoV-2 pathogen. Proxy measures such as MS2 bacteriophages and aerosolised sodium may not be generalisable to the SARS-CoV-2 pathogen.

None of the clinical research occurred during an actual pandemic/epidemic setting, and studies assessing user compliance and discomfort may not be generalisable to such scenarios. As interventions were tested in highly controlled environments, they may not be generalisable to an outbreak setting, in which there may be system-wide disorganisation, resource overload, extended use times and limited personnel.

Our findings align with the current research base. There has been significant interest in pandemic preparedness, including cost-benefit analyses of stockpiling, methods to conserve ventilators, infection control modelling and strategies to improve surge capacity. ${ }^{88-91}$ In previous outbreaks such as Ebola and influenza, hospital leaders have noted the importance of rapid PPE acquisition in response to sudden spikes in demand. ${ }^{92} 93$ However, such efforts can fail to meet demand in times of pandemic, such as with COVID-19. In addition, willingness of health providers to work during pandemics is associated with their perception of safety. ${ }^{94-97}$ Absenteeism may cause reduction in surge capacity or even basic staffing if there are mask shortages for providers. ${ }^{94-9698}$ The need to conserve available PPE for healthcare providers during the COVID-19 pandemic has informed guidelines for PPE use in lower risk groups, such as asymptomatic community members, 
Table 9 Summary of studies involving unconventional mask replacements or modifications

\begin{tabular}{|c|c|c|c|c|c|}
\hline Citation & Study design & Details of mask & Total sample size & Key findings & Limitations \\
\hline Au et $a l^{45}$ & $\begin{array}{l}\text { Randomised } \\
\text { trial with control, } \\
\text { unblinded }\end{array}$ & $\begin{array}{l}\text { Totobobo masks } \\
\text { (compact reusable } \\
\text { mask made of plastic } \\
\text { material trimmed to } \\
\text { user's face, filtered } \\
\text { by disposable high- } \\
\text { efficiency particulate } \\
\text { air filter) }\end{array}$ & $\begin{array}{l}\text { Intervention arm: } \\
22 \text { healthy } \\
\text { volunteers } \\
\text { Control arm: } \\
\text { crossover design } \\
\text { with same } \\
\text { participants }\end{array}$ & $\begin{array}{l}\text { Median reduction } \\
\text { in airborne particle } \\
\text { counts was } \\
\text { significantly higher } \\
\text { for N95 than Totobo } \\
\text { masks. }\end{array}$ & $\begin{array}{l}\text { Potential conflicts } \\
\text { of interest (study } \\
\text { investigator was } \\
\text { trained by inventor } \\
\text { of mask), may not } \\
\text { be generalisable to } \\
\text { other face shapes, } \\
\text { small sample size. }\end{array}$ \\
\hline Quan et $a l^{84}$ & Preclinical & $\begin{array}{l}\text { Surgical masks with } \\
\text { salt-infiltrated filter } \\
\text { for virus deactivation } \\
\text { system }\end{array}$ & NR & $\begin{array}{l}\text { Salt-coated filters } \\
\text { had high efficacy } \\
\text { in deactivating } \\
\text { H1N1/H5N1 } \\
\text { viruses and higher } \\
\text { filtration efficiency } \\
\text { in comparison to } \\
\text { untreated filters. }\end{array}$ & $\begin{array}{l}\text { Limited to animal } \\
\text { models, controlled } \\
\text { laboratory settings, } \\
\text { may not be } \\
\text { comparable against } \\
\text { other viruses }\end{array}$ \\
\hline Rengasamy et a/ ${ }^{44}$ & Preclinical & $\begin{array}{l}\text { Cloth masks } \\
\text { (sweatshirts, T-shirts, } \\
\text { towels, scarves and } \\
\text { commercial cloth } \\
\text { masks) }\end{array}$ & $\begin{array}{l}\text { Intervention arm: } \\
\text { three models of } \\
\text { five types of cloth } \\
\text { Control arm: } \\
\text { one N95 model }\end{array}$ & $\begin{array}{l}\text { There was a wide } \\
\text { variation in penetration } \\
\text { of common fabric } \\
\text { materials and cloth } \\
\text { masks. Penetration } \\
\text { levels for aerosols was } \\
\text { significantly higher for } \\
\text { fabrics versus control } \\
\text { N95s. }\end{array}$ & $\begin{array}{l}\text { Limited samples } \\
\text { tested, fabrics } \\
\text { were not worn or } \\
\text { laundered, face } \\
\text { seal leakage was } \\
\text { not measured, } \\
\text { human subjects are } \\
\text { necessary. }\end{array}$ \\
\hline
\end{tabular}

HCP, healthcare provider; NR, not reported.

and prompted research priorities regarding decisionmaking, such as whether surgical masks are as effective against COVID-19 as N95 respirators. ${ }^{99-101}$

Strengths of our systematic scoping review included a robust search of the literature after consultation with a research librarian. This included further hand search of citations of included articles and reviews, and a search of grey literature, including preprint databases. We undertook duplicate screening, extraction and evidence grading by at least two independent reviewers. Limitations include the restriction of examined studies to those published in English and to the last 25 years. Furthermore, we were limited to the quality of the evidence base in the search yield.

The US Food and Drug Administration (FDA) issued a guidance in May 2020 to provide recommendations for sponsors of decontamination and bioburden reduction systems about what information should be included in a pre-emergency use authorisation (pre-EUA) and/or EUA request to help facilitate FDA's efficient review of such request. ${ }^{102}$ This policy was intended to remain in effect only for the duration of the COVID-19 pandemic. As this guidance was issued subsequent to design and execution of the studies we have reviewed, we did not seek to measure their published results retroactively against the FDA guidelines. Future studies aimed at respirator conservation (including decontamination, reuse and use beyond manufacturer's expiry date) should consider these guidelines during protocol design.

Ultimately, we recommend further clinical research on mask conservation strategies, both in the current COVID-19 context as well as in preparation for any future disease outbreaks. Higher quality research, especially RCTs, is necessary for determining whether mask conservation strategies are effective against the SARS-CoV-2 pathogen specifically. While deviations from standard of care may be necessary in times of PPE shortage, it is important that evidence-informed decisions are made for both patient and provider safety.

\section{CONCLUSION}

Promising strategies for mask conservation in the context of pandemics and epidemics include use of 


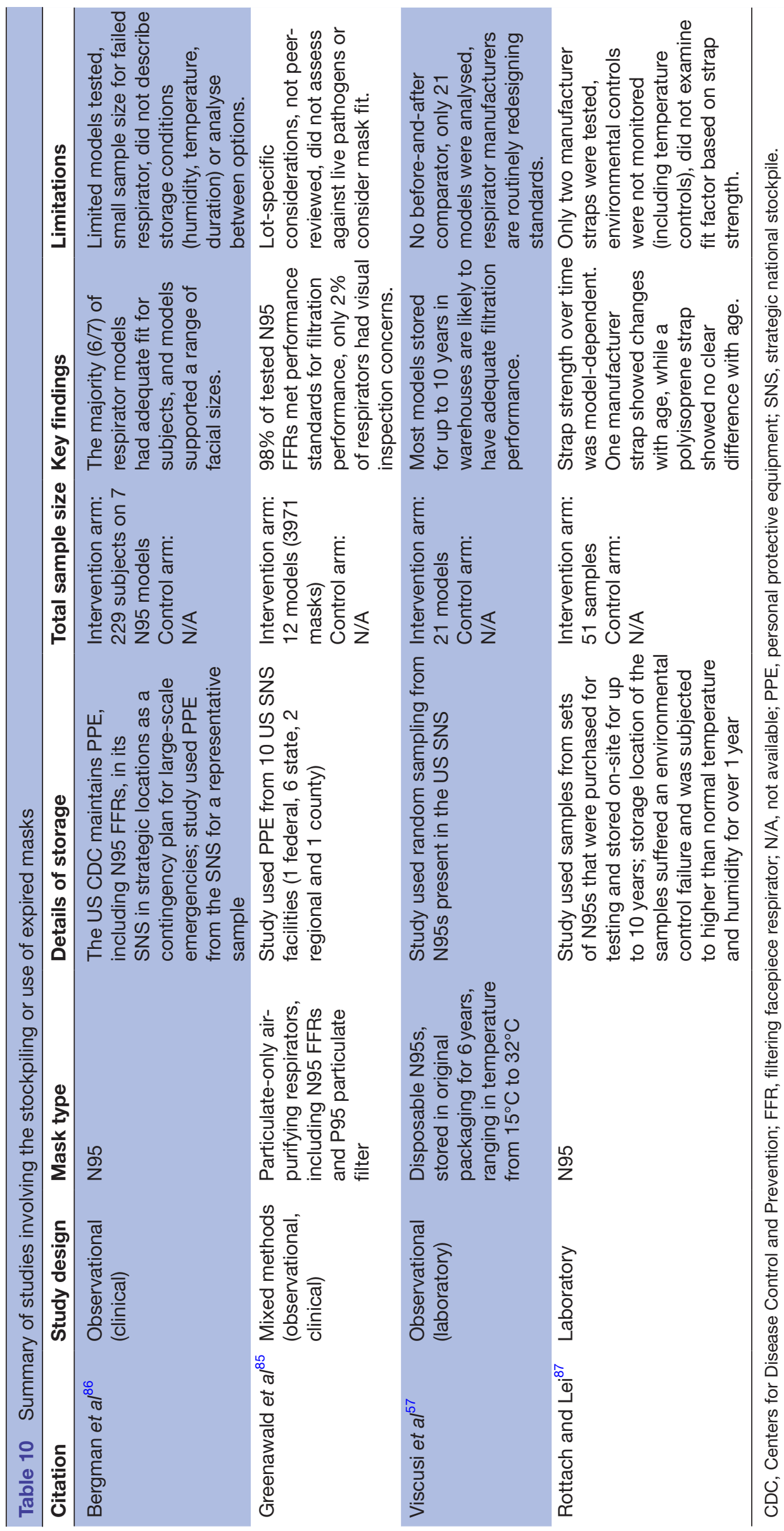


Table 11 Results of non-peer-reviewed literature

\begin{tabular}{lll}
\hline Source & Details of source & Examples of identified strategies
\end{tabular}

$\begin{array}{lll}\text { DuckDuckGo }^{30} & \begin{array}{l}\text { First } 200 \text { search results } \\ \text { on } 8 \text { April 2020, sorted by } \\ \text { relevance }\end{array} & \begin{array}{l}\text { Homemade cloth masks, mask drives, outsource production to } \\ \text { unconventional suppliers, use of bandanas as masks, use of gas masks } \\ \text { instead of face masks. }\end{array}\end{array}$

JAMA Call to Action First 200 suggestions on the Supply drives, cancellation of elective/cosmetic surgeries to conserve forum $^{16} \quad$ Call to Action forum, sorted supply, snorkel masks, buy back PPE from community sources, threedimensional (3D) printing, homemade cloth masks, use of bandanas or shirts as masks, use of constructive company masks, use of gas masks, use of vacuum cleaner bags, home air conditioner filters, racquetball/ sports glasses, use of spill containment pads, creation of face shields using a clear A4 page, recycled plastic bottles into face shields, rotation of worn masks.

\begin{tabular}{lll} 
Google News $^{31}$ & $\begin{array}{l}\text { First } 100 \text { search results as } \\
\text { of } 8 \text { April 2020, sorted by } \\
\text { relevance }\end{array}$ & $\begin{array}{l}\text { Cloth masks, 3D printing face shields, mask drives, use of garbage bags } \\
\text { as PPE, use of T-shirts, rotation of worn masks, sports dryers. }\end{array}$ \\
$\begin{array}{l}\text { LexisNexis } \\
\text { Academic }^{32}\end{array}$ & $\begin{array}{l}\text { First } 100 \text { search results } \\
\text { categorised as News, as of } \\
8 \text { April 2020 }\end{array}$ & $\begin{array}{l}\text { Cloth masks, mask drives, ski goggles or scuba diving gear as masks, } \\
\text { masks made from coffee filters and cotton bandages, use of T-shirts as } \\
\text { mask, 3D printing. }\end{array}$ \\
\hline
\end{tabular}

JAMA, Journal of the American Medical Association; PPE, personal protective equipment.

stockpiled masks, extended wear of disposable masks, and UV-based methods for decontamination. Strategies that were found to be less effective included the use of cloth masks, layering multiple surgical masks and re-donning previously used respirators. However, there remains uncertainty regarding the effectiveness of these strategies in a clinical setting, as well as their generalisability to COVID-19. Further research is needed prior to clinical implementation.

\footnotetext{
Author affiliations

${ }^{1}$ Faculty of Medicine, University of Toronto, Toronto, Ontario, Canada

${ }^{2}$ Institute of Health Policy Management and Evaluation, University of Toronto,

Toronto, Ontario, Canada

${ }^{3}$ Division of Emergency Medicine, Department of Medicine, University of Toronto, Toronto, Ontario, Canada

${ }^{4}$ Department of Emergency Medicine, University Health Network, Toronto, Ontario, Canada

${ }^{5}$ Division of Emergency Medicine, Department of Family and Community Medicine, University of Toronto, Toronto, Ontario, Canada
}

\section{Twitter Jennifer M Bryan @DrJBryan}

Acknowledgements Thank you to Kaitlin Fuller from Gerstein Science Information Centre, University of Toronto for her assistance and guidance in creation of the search strategy.

Contributors AK, JMB and SMF conceived the study. SMF supervised the conduct of the scoping review and data collection. AK, SK, TG and MY drafted the abstract and completed full-text screening, data analysis and grading. JMB and SMF addressed any discrepancies and validated results. AK, JMB and SMF drafted the manuscript, and all authors contributed substantially to its revision.

Funding The authors have not declared a specific grant for this research from any funding agency in the public, commercial or not-for-profit sectors.

Competing interests None declared.

Patient consent for publication Not required.

Provenance and peer review Not commissioned; externally peer reviewed.

Data availability statement All data relevant to the study are included in the article or uploaded as supplemental information. Data are available on reasonable request.
Supplemental material This content has been supplied by the author(s). It has not been vetted by BMJ Publishing Group Limited (BMJ) and may not have been peer-reviewed. Any opinions or recommendations discussed are solely those of the author(s) and are not endorsed by BMJ. BMJ disclaims all liability and responsibility arising from any reliance placed on the content. Where the content includes any translated material, BMJ does not warrant the accuracy and reliability of the translations (including but not limited to local regulations, clinical guidelines, terminology, drug names and drug dosages), and is not responsible for any error and/or omissions arising from translation and adaptation or otherwise.

Open access This is an open access article distributed in accordance with the Creative Commons Attribution Non Commercial (CC BY-NC 4.0) license, which permits others to distribute, remix, adapt, build upon this work non-commercially, and license their derivative works on different terms, provided the original work is properly cited, appropriate credit is given, any changes made indicated, and the use is non-commercial. See: http://creativecommons.org/licenses/by-nc/4.0/.

\section{ORCID iDs}

Abirami Kirubarajan http://orcid.org/0000-0001-9807-5024

Steven Marc Friedman http://orcid.org/0000-0002-7871-3583

\section{REFERENCES}

1 Messonnier NAG, Bell M, Kuhar DT. COVID-19 update: optimization strategies for healthcare personal protective equipment (PPE), 2020. Available: https://stacks.cdc.gov/view/cdc/86165/cdc_ 86165_DS1.pdf

2 WHO. Rational use of personal protective equipment for coronavirus disease 2019 (COVID-19) 2020. [Epub ahead of print: WHO/2019-nCov/IPC_PPE_use/2020.3] https://www.who.int/ publications-detail-redirect/rational-use-of-personal-protectiveequipment-for-coronavirus-disease-(covid-19)-and-considerationsduring-severe-shortages

3 Chaib F. Shortage of personal protective equipment endangering health workers worldwide, 2020. Available: https://www.who.int/ news-room/detail/03-03-2020-shortage-of-personal-protectiveequipment-endangering-health-workers-worldwide

4 Phys ACE. COVID-19: personal protective equipment (PPE) during the pandemic, 2020. Available: https://www.acep.org/patient-care/ policy-statements/covid-19-personal-protective-equipment-ppeduring-the-pandemic/

5 CAEP. Recommendations for PPE in the emergency department during COVID-19, 2020. Available: https://caep.ca/wp-content/ uploads/2020/04/AGMP-V6-F-clean-1-1-DK-Formatted.pdf

6 Xiao Y, Torok ME. Taking the right measures to control COVID-19. Lancet Infect Dis 2020;20:523-4. 
7 Wang G, Zhang Y, Zhao J, et al. Mitigate the effects of home confinement on children during the COVID-19 outbreak. The Lancet 2020;395:945-7.

8 Gamage B, Moore D, Copes R, et al. Protecting health care workers from SARS and other respiratory pathogens: a review of the infection control literature. Am J Infect Control 2005;33:114-21.

9 Fischer WA, Weber DJ, Wohl DA. Personal protective equipment: protecting health care providers in an Ebola outbreak. Clin Ther 2015;37:2402-10.

10 Marshall C, Kelso A, McBryde E, et al. Pandemic (H1N1) 2009 risk for frontline health care workers. Emerg Infect Dis 2011;17:1000-6.

$11 \mathrm{WHO}$. Shortage of PPE endangering health workers worldwide, 2020. Available: https://www.who.int/news-room/detail/03-032020-shortage-of-personal-protective-equipment-endangeringhealth-workers-worldwide

12 Ranney ML, Griffeth V, Jha AK. Critical supply shortages - the need for ventilators and personal protective equipment during the Covid-19 pandemic. N Engl J Med Overseas Ed 2020;382:e41.

13 Lancet T. COVID-19 resource centre, 2020. Available: https://www. thelancet.com/coronavirus

14 Chang D, Xu H, Rebaza A, et al. Protecting health-care workers from subclinical coronavirus infection. Lancet Respir Med 2020;8:e13.

15 CDC. Strategies for optimizing the supply of Facemasks, 2020. Available: https://www.cdc.gov/coronavirus/2019-ncov/hcp/ppestrategy/face-masks.html

16 Bauchner $\mathrm{H}$, Fontanarosa PB, Livingston $\mathrm{EH}$. Conserving supply of personal protective equipment-a call for ideas. JAMA 2020;323:1911.

17 Livingston $\mathrm{E}$, Desai A, Berkwits M. Sourcing personal protective equipment during the COVID-19 pandemic. JAMA 2020;323:1912.

18 Bhattacharya S, Mahbub Hossain M, Singh A, et al. Addressing the shortage of personal protective equipment during the COVID-19 pandemic in India-A public health perspective. AIMS Public Health 2020;7:223-7.

19 Peters MDJ, Godfrey C, Mclnerney P, et al. Chapter 11: scoping reviews (2020 version). In: Aromataris E, Munn Z, eds. JBI manual for evidence synthesis. Adelaide, Australia: JBI, 2020. https:// synthesismanual.jbi.global

20 Tricco AC, Lillie E, Zarin W, O'Brien KK, et al. PRISMA extension for scoping reviews (PRISMA-ScR): checklist and explanation. Ann Intern Med 2018;169:467.

21 OSF. Preprint archive search, 2020. Available: https://osf.io/ preprints/discover?q=Covid-19\%200R\%202019-ncov\%200R\% $20 \% 22$ novel\%20coronavirus\%202019\%22\%200R\%20\%222019\% 20novel\%20coronavirus\%222020

22 Kirubarajan A, Khan S, Got T, et al. Protocol for scoping review: mask shortage during epidemics and pandemics. The Open Science Framework 2020 https://osf.io/y4r2t/

23 Google. Foam search http://googlefoam.com/\#gsc.tab=0

24 COVID-19 expert. Available: https://www.cdc.gov/coronavirus/ 2019-ncov/hcp/ppe-strategy/decontamination-reuse-respirators. html

25 Prevention CfDCa. Decontamination and reuse of filtering Facepiece respirators using contingency and crisis capacity strategies, 2020. Available: https://www.cdc.gov/coronavirus/ 2019-ncov/hcp/ppe-strategy/decontamination-reuse-respirators. html

26 Prevention CfDCa. Release of Stockpiled N95 filtering Facepiece respirators beyond the ManufacturerDesignated shelf life: considerations for the COVID-19 response, 2020.

27 Prevention CfDCa. PPE CASE Reports 2020 [updated March 25, 2020. Available from:. Available: https://www.cdc.gov/niosh/npptl/ ppecase.html [Accessed April 24 2020].

28 Canada IPaC. Conservation and decontamination N95 Facemasks and PPE. Available: https://ipac-canada.org/reprocessing-of-ppe. php

29 Canada Go. Infection prevention and control for COVID-19. second interim guidance for acute healthcare settings. Available: https:// www.canada.ca/en/public-health/services/diseases/2019-novelcoronavirus-infection/health-professionals/interim-guidance-acutehealthcare-settings.html\#a4.10

30 DuckDuckGo. DuckDuckGo, 2020. Available: https://duckduckgo. com/

31 News G. COVID-19 news. Available: https://news.google.com/ topstories?hl=en-CA\&gl=CA\&ceid=CA:en

32 LexisNexis. LexisNexis®Academic, 2020. Available: https://www. lexisnexis.ca/en-ca/products/lexisnexis-academic.page

33 Allen C. Evidence aid. coronavirus (COVID-19): evidence collection, 2020. Available: https://www.evidenceaid.org/coronavirus-covid19-evidence-collection/
34 BMC. Coronavirus research highlights, 2020. Available: https:// www.biomedcentral.com/collections/Coronavirus

35 Medicine TNEJo. Coronavirus (Covid-19), 2020. Available: https:// www.nejm.org/coronavirus

36 Nature S. SARS-CoV-2 and COVID-19, 2020. Available: https:// www.springernature.com/gp/researchers/campaigns/coronavirus

37 Howick JCl, Glasziou P, Greenhalgh T. The 2011 Oxford CEBM evidence levels of evidence. Oxford: Oxford Center for EvidenceBased Medicine, 2011.

38 Krithikadatta J, Gopikrishna V, Datta M. CRIS guidelines (checklist for reporting in-vitro studies): a concept note on the need for standardized guidelines for improving quality and transparency in reporting in-vitro studies in experimental dental research. J Conserv Dent 2014;17:301.

39 OECD. Series on principles of good laboratory practice and compliance monitoring, number 14, Advisory document of the Working group on good laboratory practice, the application of the principles of GLP to in vitro studies 2004;98 http://www.oecd.org/ chemicalsafety/testing/oecdseriesonprinciplesofgoodlaboratorypr acticeglpandcompliancemonitoring.htm

40 Macleod MR, Fisher M, O'Collins V, et al. Good laboratory practice: preventing introduction of bias at the bench. Stroke 2009;40:e50-2.

41 McGrath JC, Drummond GB, McLachlan EM, et al. Guidelines for reporting experiments involving animals: the ARRIVE guidelines. $\mathrm{Br}$ J Pharmacol 2010;160:1573-6.

42 Baginskait J. Scientific quality issues in the design and reporting of bioscience research: a systematic study of randomly selected original in vitro. CAMARADES Monogr 2012.

43 Maclntyre CR, Seale H, Dung TC, et al. A cluster randomised trial of cloth masks compared with medical masks in healthcare workers. BMJ Open 2015;5:e006577.

44 Rengasamy S, Eimer B, Shaffer RE. Simple respiratory protectionevaluation of the filtration performance of cloth masks and common fabric materials against $20-1000 \mathrm{~nm}$ size particles. Ann Occup Hyg 2010;54:789-98.

45 Au SSW, Gomersall CD, Leung P, et al. A randomised controlled pilot study to compare filtration factor of a novel non-fit-tested highefficiency particulate air (Hepa) filtering facemask with a fit-tested N95 mask. J Hosp Infect 2010;76:23-5.

46 Canada Go. Reprocessing of N95 Respirators for Healthcare Professionals - Notice, 2020. Available: https://www.canada.ca/en/ health-canada/services/drugs-health-products/medical-devices/ activities/announcements/covid19-notice-reprocessing-n95respirators-health-professionals.html

47 Fisher EM, Williams JL, Shaffer RE. Evaluation of microwave steam bags for the decontamination of filtering facepiece respirators. PLoS One 2011;6:e18585.

48 Mills D, Harnish DA, Lawrence C, et al. Ultraviolet germicida irradiation of influenza-contaminated N95 filtering facepiece respirators. Am J Infect Control 2018;46:e49-55

49 Heimbuch BK, Wallace WH, Kinney K, et al. A pandemic influenza preparedness study: use of energetic methods to decontaminate filtering facepiece respirators contaminated with $\mathrm{H} 1 \mathrm{~N} 1$ aerosols and droplets. Am J Infect Control 2011;39:e1-9.

50 Lore MB, Heimbuch BK, Brown TL, et al. Effectiveness of three decontamination treatments against influenza virus applied to filtering facepiece respirators. Ann Occup Hyg 2012;56:92-101.

51 Richter W. Investigating decontamination and reuse of respirators in public health emergencies FDA 2016, 2016. Available: https://www. fda.gov/media/136386/download

52 Heimbuch BK, Kinney K, Lumley AE, et al. Cleaning of filtering facepiece respirators contaminated with mucin and Staphylococcus aureus. Am J Infect Control 2014;42:265-70.

53 Lin T-H, Tang F-C, Hung P-C, et al. Relative survival of Bacillus subtilis spores loaded on filtering facepiece respirators after five decontamination methods. Indoor Air 2018;28:754-62.

54 Lin T-H, Chen C-C, Huang S-H, et al. Filter quality of electret masks in filtering 14.6-594 nm aerosol particles: effects of five decontamination methods. PLoS One 2017;12:e0186217.

55 Viscusi DJ, King WP, Shaffer RE. Effect of decontamination on the filtration efficiency of two filtering Facepiece respirator models. J Int Soc Respir Prot 2007;24:93.

56 Bergman MS, Viscusi DJ, Heimbuch BK, et al. Evaluation of multiple (3-Cycle) decontamination processing for filtering Facepiece respirators. J Eng Fiber Fabr 2010;5:155892501000500.

57 Viscusi DJ, Bergman M, Sinkule E, et al. Evaluation of the filtration performance of $21 \mathrm{~N} 95$ filtering face piece respirators after prolonged storage. Am J Infect Control 2009;37:381-6.

58 Salter WB, Kinney K, Wallace WH, et al. Analysis of residual chemicals on filtering facepiece respirators after decontamination. $J$ Occup Environ Hyg 2010;7:437-45. 
59 Viscusi DJ, Bergman MS, Eimer BC, et al. Evaluation of five decontamination methods for filtering facepiece respirators. Ann Occup Hyg 2009;53:815-27.

60 Lindsley WG, Martin SB, Thewlis RE, et al. Effects of ultraviolet germicidal irradiation (UVGI) on N95 respirator filtration performance and structural integrity. J Occup Environ Hyg 2015;12:509-17.

61 Nemeth C, Laufersweiler D, Polander E, et al. Preparing for an influenza pandemic: Hospital acceptance study of filtering Facepiece respirator decontamination using ultraviolet germicidal irradiation. J Patient Saf 2020;16:117-22.

62 Viscusi DJ, Bergman MS, Novak DA, et al. Impact of three biological decontamination methods on filtering facepiece respirator fit, odor, comfort, and donning ease. J Occup Environ Hyg 2011;8:426-36.

63 Coulliette AD, Perry KA, Edwards JR, et al. Persistence of the 2009 pandemic influenza A ( $\mathrm{H} 1 \mathrm{~N} 1)$ virus on $\mathrm{N} 95$ respirators. Appl Environ Microbiol 2013;79:2148-55.

64 Fisher E, Shaffer R. Survival of bacteriophage MS2 on filtering Facepiece respirator Coupons. Applied Biosafety 2010;15:71-6.

65 Fisher EM, Richardson AW, Harpest SD, et al. Reaerosolization of MS2 bacteriophage from an N95 filtering facepiece respirator by simulated coughing. Ann Occup Hyg 2012;56:315-25.

66 Duarte LR MC, Cavalcante NJ, Bammann RH, et al. Estado de conservação de respiradores PFF-2 após uso Na rotina hospitalar Revista dA Escola de Enfermagem dA USP 2010;44:1011-6.

67 Brady TM, Strauch AL, Almaguer CM, et al. Transfer of bacteriophage MS2 and fluorescein from N95 filtering facepiece respirators to hands: measuring fomite potential. $J$ Occup Environ Hyg 2017;14:898-906.

68 Radonovich LJ, Shenal BV, Hodgson M. Respirator tolerance in health care workers. JAMA 2009;301:36.

69 Shenal BV, Radonovich LJ, Cheng J, et al. Discomfort and exertion associated with prolonged wear of respiratory protection in a health care setting. J Occup Environ Hyg 2012;9:59-64.

70 Bergman MS, Viscusi DJ, Zhuang Z, et al. Impact of multiple consecutive donnings on filtering facepiece respirator fit. Am J Infect Control 2012;40:375-80.

71 Vuma CD, Manganyi J, Wilson K, et al. The effect on fit of multiple consecutive Donning and Doffing of N95 filtering Facepiece respirators. Ann Work Expo Health 2019;63:930-6.

72 Pillai SK, Beekmann SE, Babcock HM, et al. Clinician beliefs and attitudes regarding use of respiratory protective devices and surgical masks for influenza. Health Security 2015;13:274-80.

73 Derrick JL, Gomersall CD. Protecting healthcare staff from severe acute respiratory syndrome: filtration capacity of multiple surgical masks. J Hosp Infect 2005;59:365-8.

74 Rebmann T, Carrico R, Wang J. Physiologic and other effects and compliance with long-term respirator use among medical intensive care unit nurses. Am J Infect Control 2013;41:1218-23.

75 Roberge RJ, Coca A, Williams WJ, et al. Surgical mask placement over N95 filtering facepiece respirators: physiological effects on healthcare workers. Respirology 2010;15:516-21.

76 Sinkule EJ, Powell JB, Goss FL. Evaluation of N95 respirator use with a surgical mask cover: effects on breathing resistance and inhaled carbon dioxide. Ann Occup Hyg 2013;57:384-98.

77 Lawrence C, Harnish DA, Sandoval-Powers M, et al. Assessment of half-mask elastomeric respirator and powered air-purifying respirator reprocessing for an influenza pandemic. Am J Infect Control 2017;45:1324-30.

78 Subhash SS, Cavaiuolo M, Radonovich LJ, et al. Effectiveness of common healthcare disinfectants against $\mathrm{H} 1 \mathrm{~N} 1$ influenza virus on reusable elastomeric respirators. Infect Control Hosp Epidemiol 2014;35:894-7.

79 Bessesen MT, Adams JC, Radonovich L, et al. Disinfection of reusable elastomeric respirators by health care workers: a feasibility study and development of standard operating procedures. Am J Infect Control 2015;43:629-34.

80 Pompeii LA, Kraft CS, Brownsword EA, Lane MA, et al. Training and fit testing of health care personnel for reusable elastomeric HalfMask respirators compared with disposable N95 respirators. JAMA 2020;323:1849-52.

81 Hines SE, Mueller N, Oliver M, et al. Qualitative analysis of origins and evolution of an elastomeric Respirator-based Hospital respiratory protection program. J Int Soc Respir Prot 2017;34:95-110.

82 Hines SE, Brown C, Oliver M, et al. User acceptance of reusable respirators in health care. Am J Infect Control 2019;47:648-55.

83 Hines SE, Brown C, Oliver M, et al. Storage and availability of elastomeric respirators in health care. Health Security 2019;17:384-92.
84 Quan F-S, Rubino I, Lee S-H, et al. Universal and reusable virus deactivation system for respiratory protection. Sci Rep 2017;7:39956

85 Greenawald L, Moore S, Yorio P. Inhalation and exhalation resistance and filtration performance of stockpiled air-purifying respirators: overall performance of nearly 4000 respirators sampled from ten stockpile facilities 2020 https://www.cdc.gov/niosh/npptl/ ppecase/pdfs/PPE-CASE-Aggregated-Stockpile-Study-03252020508.pdf

86 Bergman M, Zhuang Z, Brochu E, et al. Fit assessment of N95 Filtering-Facepiece respirators in the U.S. centers for disease control and prevention strategic national stockpile. J Int Soc Respir Prot 2015;32:50-64.

87 Rottach DR, Lei Z. Stockpiled N95 filtering Facepiece respirator polyisoprene strap performance. J Int Soc Respir Prot 2017;34:6980.

88 Baracco G, Eisert S, Eagan A, et al. Comparative cost of Stockpiling various types of respiratory protective devices to protect the health care workforce during an influenza pandemic. Disaster Med Public Health Prep 2015;9:313-8.

89 Huang H-C, Araz OM, Morton DP, et al. Stockpiling ventilators for influenza pandemics. Emerg Infect Dis 2017;23:914-21.

90 Wein LM, Atkinson MP. Assessing infection control measures for pandemic influenza. Risk Anal 2009;29:949-62.

91 Hick JL ES, Hanfling D, Kissoon N, et al. Task force for mass critical care. surge capacity principles: care of the critically ill and injured during pandemics and disasters: chest consensus statement. Chest 2014:146:e1S-6.

92 Bleasdale SC, Sikka MK, Moritz DC, et al. Experience of Chicagoland acute care hospitals in preparing for Ebola virus disease, 2014-2015. J Occup Environ Hyg 2019;16:582-91.

93 Bourlon MT, Macias AE, de la Torre A, et al. Organization of a third-level care hospital in Mexico City during the 2009 influenza epidemic. Arch Med Res 2009;40:681-6.

94 Balicer RD, Barnett DJ, Thompson CB, et al. Characterizing hospital workers' willingness to report to duty in an influenza pandemic through threat- and efficacy-based assessment. BMC Public Health 2010;10:436.

95 Martin SD, Brown LM, Reid WM. Predictors of Nurses' Intentions to Work During the 2009 Influenza A (H1N1) Pandemic. AJN, American Journal of Nursing 2013;113:24-31.

96 Garrett AL, Park YS, Redlener I. Mitigating absenteeism in hospital workers during a pandemic. Disaster Med Public Health Prep 2009;3 Suppl 2:S141-7.

97 Blackwell T. Canadian nurses treating COVID-19 patients cite unsafe-work laws to demand N95 masks: national post 2020 https://nationalpost.com/health/canadian-nurses-working-withcovid-19-patients-demand-legal-right-to-wear-n95-masks

98 Campbell D, Steward H. Doctors threaten to quit NHS over shortage of protective kit: the guardian, 2020. Available: https:// www.theguardian.com/world/2020/mar/24/doctors-threaten-toquit-over-protective-equipment-shortage

99 Yu X, Yang R, Yu X. COVID-19 transmission through asymptomatic carriers is a challenge to containment. Influenza Other Respir Viruses 2020;14:474-5.

100 Prevention. CfDCa. Strategies for optimizing the supply of facemasks, 2020. Available: https://www.cdc.gov/coronavirus/ 2019-ncov/hcp/ppe-strategy/face-masks.html

101 (NIOSH) TNIfOSaH. Pandemic planning: options to prolong existing and surge capacity supplies of respirators during infection with novel influenza A viruses associated with severe disease, 2020. Available: https://www.cdc.gov/niosh/topics/hcwcontrols/ pandemic-planning.htm

102 U.S. Department of Health and Human Services Food and Drug Administration Center for Devices and Radiological Health (CDRH), Office of Product Evaluation and Quality (OPEQ). Recommendations for Sponsors requesting euas for decontamination and bioburden reduction systems for surgica masks and respirators during the coronavirus disease 2019 (COVID19) Public health emergency - guidance for industry and food and drug administration staff, 2020. Available: https://www. fda.gov/media/138362/download

103 Canada PHAo. About non-medical masks and face coverings, 2020. Available: https://www.canada.ca/en/public-health/services/ diseases/2019-novel-coronavirus-infection/prevention-risks/ instructions-sew-no-sew-cloth-face-covering.html

104 European Centre for Disease Prevention and Control. Safe use of personal protective equipment in the treatment of infectious diseases of high consequence. Stockholm: ECDC, 2014.

105 Brosseau L, Berry Ann R. N95 respirators and surgical masks, 2020. Available: https://blogs.cdc.gov/niosh-science-blog/2009/10/14/n95/ 
106 3M. Surgical N95 vs. standard N95 - which to consider? 2020. Available: https://multimedia.3m.com/mws/media/17945720/ surgical-n95-vs-standard-n95-which-to-consider.pdf

107 Elsevier. Novel coronavirus information center. Amsterdam: Elsevier, 2020.

108 BMJ T. BMJ's Coronavirus (covid-19) Hub. Available: https://www. bmj.com/coronavirus
109 Fisher EM, Shaffer RE. A method to determine the available UV-C dose for the decontamination of filtering facepiece respirators. $J$ Appl Microbiol 2011;110:287-95.

110 Woo M-H, Grippin A, Anwar D, et al. Effects of relative humidity and spraying medium on UV decontamination of filters loaded with viral aerosols. Appl Environ Microbiol 2012;78:5781-7.

111 Vo E, Rengasamy S, Shaffer R. Development of a test system to evaluate procedures for decontamination of respirators containing viral droplets. Appl Environ Microbiol 2009;75:7303-9. 